Materials and Components

Technology Division

Materials and Components

Technology Division

$I-32356 \quad$ DR $0332-8$

(3)

ANL-87-21

Materials and Components

Technology Division

Materials and Components

Technology Division

Materials and Components

Technology Division

Materials and Components

Technology Division

Materials and Components

Technology Division

Materials and Components

Technology Division

Materials and Components

Technology Division

Materials and Components

Technology Division
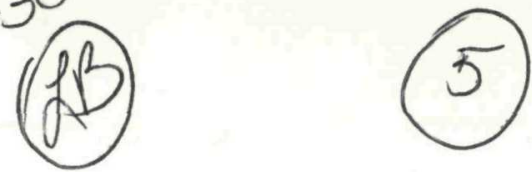

\title{
Assessment of Impact of Advanced Energy Transmission Fluids on District Heating and Cooling Systems (Phase I)
}

Materials and Components

Technology Division Materials and Components Tohnalogy Division

Materials and Components

Technology Division Materials and Components

Technology Division Materials and Components

Technology Division Materials and Components

Technology Division Materials and Components

Technology Division

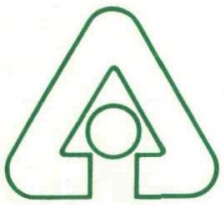

Argonne National Laboratory, Argonne, Illinois 60439

operated by The University of Chicago

for the United States Department of Energy under Contract W-31-109-Eng-38

Materials and Components

Technology Division Materials and Components

Technology Division Materials and Components

Technology Division Materials and Components

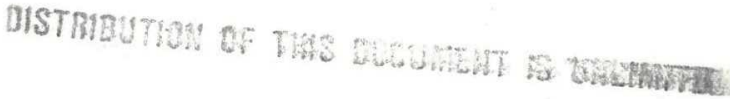

Technology Division 


\section{DISCLAIMER}

Portions of this document may be illegible in electronic image products. Images are produced from the best available original document. 
Argonne National Laboratory, with facilities in the states of Illinois and Idaho, is owned by the United States government, and operated by The University of Chicago under the provisions of a contract with the Department of Energy.

\section{DISCLAIMER}

This report was prepared as an account of work sponsored by an agency of the United States Government. Neither the United States Government nor any agency thereof, nor any of their employees, makes any warranty, express or implied, or assumes any legal liability or responsibility for the accuracy, completeness, or usefulness of any information, apparatus, product, or process disclosed, or represents that its use would not infringe privately owned rights. Reference herein to any specific commercial product, process, or service by trade name, trademark, manufacturer, or otherwise, does not necessarily constitute or imply its endorsement, recommendation, or favoring by the United States Government or any agency thereof. The views and opinions of authors expressed herein do not necessarily state or reflect those of the United States Government or any agency thereof.

Printed in the United States of America Available from

National Technical Information Service

U. S. Department of Commerce

5285 Port Royal Road

Springfield, VA 22161

NTIS price codes

Printed copy: A04

Microfiche copy: A01 


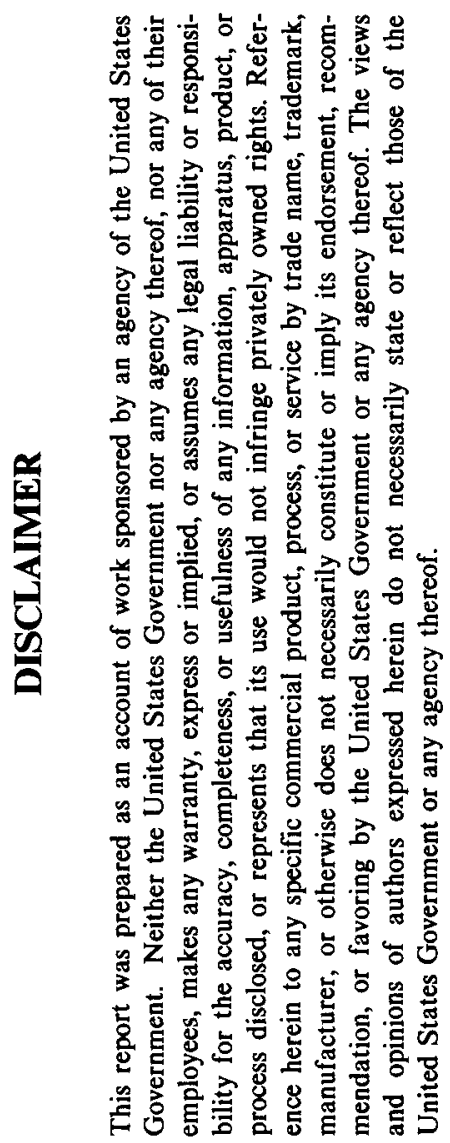

Distribution Categories:

Energy Conservation-Buildings and Community Systems (UC-95D)

Solar Heating and Cooling-Active (UC-59A)

ANL $--87-21$

DE88 001589

\author{
ARGONNE NATIONAL LABORATORY \\ 9700 South Cass Avenue \\ Argonne, Illinois 60439
}

\title{
ASSESSMENT OF IMPACT OF ADVANCED ENERGY TRANSMISSION FLUIDS ON DISTRICT HEATING AND COOLING SYSTEMS (PHASE I)
}

by

K. E. Kasza and M. M. Chen

Materials and Components Technology Division

\section{MASTER}

September 1987

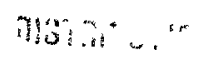


Table of Contents

$\underline{\text { Page }}$

Abstract. .....................................

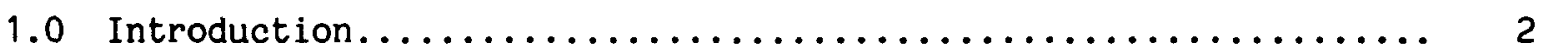

1.1 Friction Reduction.......................... 4

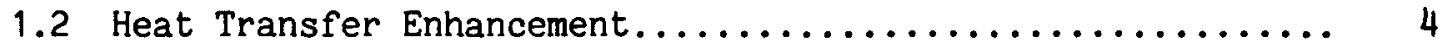

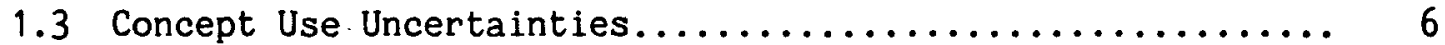

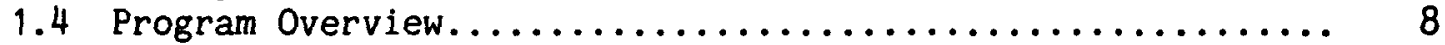

1.5 Preliminary Proof-of-Concept Results................. 9

2.0 Potential Benefits for New Installations............... 13

2.1 General Benefits................................ 14

2.1.1 Reduction of Flow Rate and Pumping Power Requirements Due to the Use of Phase Change Slurries...... 14

2.1.2 Reduction of Storage Tank Volume and Heat Loss Due to the Use of Phase Change Slurries.......... 16

2.1.3 Heat Transfer Enhancement and Heat Exchanger Size Reductions Due to the Use of Phase Change Slurries.. 17

2.1.4 Pressure Drop and Pumping Power Reductions Due to Friction-Reducing Additives................ 17

2.2 Specific Benefits for District Cooling Applications....... 18

2.2.1 Heat Capacity Increases and Flow Rate and Storage Tank Volume Reductions Due to Phase Change Slurry... 19

2.2.2 Pressure Drop and Pumping Power Reductions at Constant Pipe Diameter................... 20 2.2.2.1 Improvements Due to Friction Reduction 2.2.2.2 Improvements Due to Phase Change Siurry 2.2.2.3 Improvements Due to Combination of Friction Reduction and Phase Change....... 22

2.2.3 Pipe Size Reductions and Associated Savings........ 22

2.3 Specific Benefits for District Heating Applications....... 23

2.3.1 Heat Capacity Increases.................... 25

2.3.2 Pressure Drop and Pumping Power Reductions for Constant Pipe Diameter...................... 25

2.3.3 Pipe Size Reduction and Associated Savings for Constant Pressure Drop or Constant Power.......... 26

3.0 Capacity Enhancement for Existing Systems.............. 27

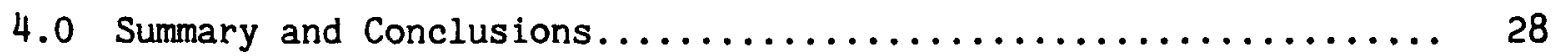

Acknowledgments..................................... 30

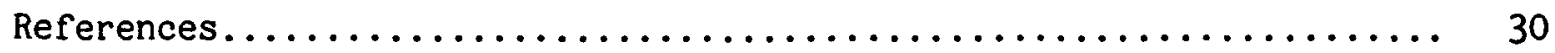


List of Figures

$\underline{\text { Page }}$

Fig. 1. Slurry Heat Transfer Test Facility................ 34

Fig. 2a. Influence of Solids Volume Loading and Friction-

Reducing Additives on Pressure Drop Associated with

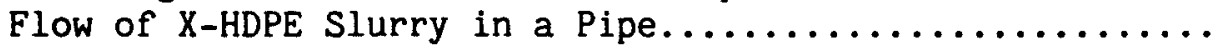

Fig. 2b. Percent Pressure Drop Change Over Water vs. Mass Flow Rate

of Slurry................................ 36

Fig. 3. Variation of Heat Transfer Nusselt Number (Nu) For

Slurry of X-HDPE and Pure Water Versus Effective Pipe

Reynolds Number (Re) for Various Slurry Loadings $(\phi) \ldots . \ldots$

Fig. 4. Assumed System for Comparison of Enhanced Energy

Transmission Fluids with Conventional Fluids in DHC

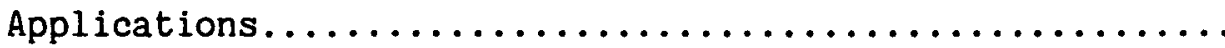

Fig. 5. Ratio of Mass Flow between Phase Change Slurry $(\dot{M}))$
and Conventional Single-Phase Sensible-Heat Fluid

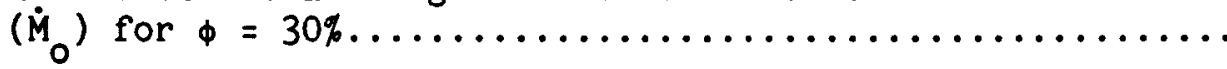

Fig. 6. Ratio of Pressure Drop between Phase Change Slurry $\left(\Delta p_{p c}\right)$ and Conventional Sensible-Heat System $\left(\Delta p_{0}\right)$ for $\phi=30 \% \ldots$

Fig. 7. Ratio of Pumping Power between Phase Change Slurry $\left(W_{p c}\right)$ and Conventional Sensible-Heat System $\left(W_{0}\right)$ for $\phi=30 \% \ldots .$.

Fig. 8. Ratio of Storage Volume between Phase Change Slurry $\left(V_{p c}\right)$ and a Conventional Single-Phase System $\left(V_{o}\right)$

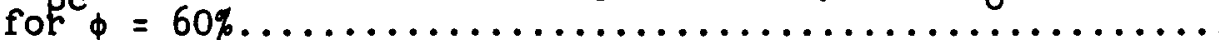

Fig. 9. Ratio of Slurry Storage Tank Heat Loss for a Phase Change Slurry System $\left(Q_{L}, R c\right)$ and a Conventional System $\left(Q_{L}, 0\right)$ for Various Source-to-Sink Total Temperature Differences, $\Delta T$...

Fig. 10. Potential Heat Transfer Enhancement Due to the Use of

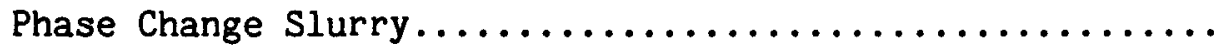

Fig. 11. Pressure Drop Reduction and Pumping Power Reduction Due to a Friction-Reducing Additive as a Function of the Reynolds Number for a Pipe of Constant Diameter...........

Fig. 12. Comparison of Coolant Flow Rate and Cold Storage Tank Volume for Ice Slush Slurry and Conventional Chilled Water

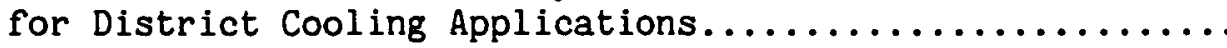

Fig. 13. Comparison of Storage Tank Heat Gain for Various Chilled

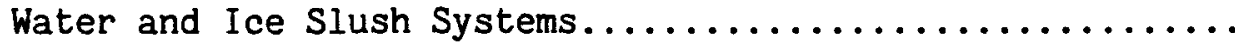


List of Figures (Contd.)

Fig. 14. Comparison of Pressure Drop for Advanced Energy

Page

Transmission Fluids with That for Conventional Fluids at

Constant Pipe Diameter......................... 48

Fig. 15. Comparison of Pumping Power for Advanced Energy

Transmission Fluids with That for Conventional Fluids at

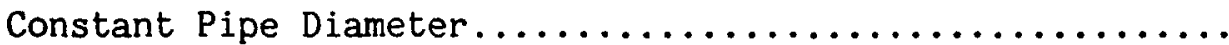

Fig. 16. Reduction of Pipe Diameter for Advanced Energy

Transmission Fluids Compared to That of Conventional Fluids

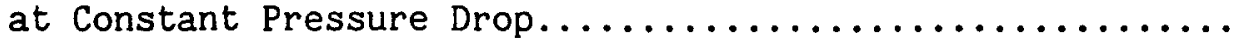

Fig. 17. Reduction of Fluid Inventory of Advanced Energy

Transmission Fluids Compared to Conventional Fluids at

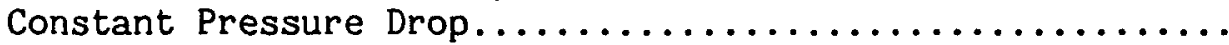

Fig. 18. Pipe Size Reductions of Advanced Energy Transmission

Fluids Compared to Conventional Fluids at Constant Power... 52

Fig. 19. Fluid Inventory Reductions of Advanced Energy

Transmission Fluids Compared to Conventional Fluids at

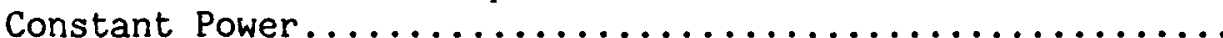

Fig. 20. Pressure Drop Reductions for Constant Pipe Diameter...... 54

Fig. 21. Pumping Power Reductions for Constant Pipe Diameter...... 55

Fig. 22. Pipe Size Reductions at Constant Pressure Drop......... 56

Fig. 23. Fluid Inventory Reductions at Constant Pressure Drop..... 57

Fig. 24. Pipe Diameter Reductions at Constant Power Compared to

Pressurized Water System....................... 58

Fig. 25. Fluid Inventory Reductions at Constant Power Compared to

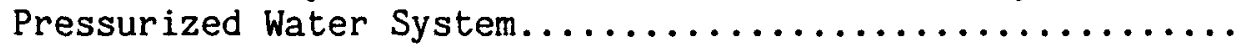

Fig. 26. Pipe Diameter Reductions at Constant Power Compared to Nonpressurized Water System....................

Fig. 27. Fluid Inventory Reductions at Constant Power Compared to

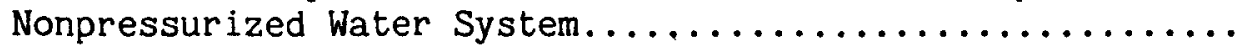

Fig. 28. Increase in Heating Capacity for Advanced Fluids Systems as Compared to Nonpressurized Water in an Existing

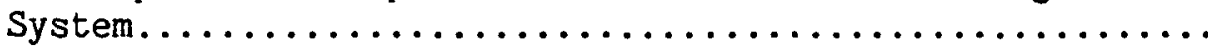

Fig. 29. Increase in Heating Capacity for Advanced Fluids Systems as Compared to Pressurized Water in an Existing System..... 


\section{List of Figures (Contd.)}

Fig. 30. Increase in Cooling Capacity for Advanced Fluids as

$\underline{\text { Page }}$

Compared to Chilled Water in an Existing Cooling System....

64

\section{List of Tables}

Table 1. Theoretical Enhancement Ratios for Thermal Conductivity and Heat Transfer Coefficients in Slurry Flow in Pipes Without Phase Change......................... 32

Table 2. Heat Capacity and Related Benefits for District Heating.... 33 
NOMENCLATURE

(Symbols, subscripts, and abbreviations)

1. English Letters

C Specific heat at constant pressure

$C_{p c}$ Specific heat of phase change slurry, based on mass weighted averaging of the constituent specific heats, $=\Sigma \Phi_{i} C_{i}$

D Pipe diameter

f Pipe friction factor

h Heat transfer coefficient

$L$ Length

$\dot{M}$ Mass flow rate

p Pressure

$\Delta \mathrm{p}$ Pressure drop

$Q \quad$ Heating or cooling capacity

$\dot{Q}$ Volumetric flow rate

$Q_{L} \quad$ Storage tank heat loss

T Temperature

$\Delta T$ Total temperature change

u Velocity

$V$ Storage tank volume

W Power

2. Greek Letters

$\Delta \quad$ Total change; e.g., $\Delta \mathrm{T}$ denotes total temperature change

$\lambda$ Latent heat of phase change material

$\checkmark \quad$ Kinematic viscosity

$\phi$ Mass fraction. If no subscript, mass fraction of phase change material.

ค Density

3. Subscripts

fr Friction reducing

- Baseline system - conventional sensible-heat system without phase change or friction reduction

npw Nonpressurized water

pc Phase change slurry

pw Pressurized water 
4. Abbreviations

$\begin{array}{ll}\text { ANL } & \text { Argonne National Laboratory } \\ \text { COP } & \text { Coefficient of performance (for a refrigeration system) } \\ \text { DHC } & \text { District heating and cooling system } \\ \text { DOE } & \text { Department of Energy } \\ \text { FI } & \text { Fluid inventory } \\ \text { FR } & \text { Friction-reducing additive } \\ \text { NPW } & \text { Nonpressurized water system } \\ \text { Nu } & \text { Heat transfer Nusselt number } \\ \text { PC } & \text { Phase change } \\ \text { PCM } & \text { Phase change materials } \\ \text { POLYOX } & \text { Common name of polyethylene oxide } \\ \text { PW } & \text { Pressurized water system } \\ \text { Re } & \text { Pipe flow Reynolds number } \\ \text { SERI } & \text { Solar Energy Research Institute } \\ \text { SHTF } & \text { Slurry Heat Transfer Test Facility (at ANL) } \\ \text { UD } & \text { Water flow } \\ \text { X-HDPE } & \text { Cross-linked high-density polyethylene }\end{array}$




\section{ASSESSMENT OF IMPACT OF ADVANCED ENERGY TRANSMISSION FLUIDS ON DISTRICT HEATING AND COOLING SYSTEMS (PHASE I)*}

by

K. E. Kasza and M. M. Chen

Materials and Components Technology Division

ARGONNE NATIONAL LABORATORY

Argonne, Illinois 60439

Abstract

Argonne National Laboratory (ANL), under sponsorship of the U.S. Department of Energy (DOE) Office of Buildings and Community Systems, has embarked upon a comprehensive, long-range program to develop highperformance advanced energy transmission fluids for use in district heating and cooling (DHC) systems. ANL has the lead technical role in this DOE program.

These advanced fluids will substantially reduce flow frictional losses and enhance energy transfer. In system enhancement scoping studies conducted by ANL, the fluids yielded potentially significant upfront capital equipment cost reductions by allowing the use of smaller pipes, pumps, heat exchangers, and storage tanks as well as reductions in operational costs. This report presents the first-phase results of assessment of impact of the advanced fluids on DHC systems. Future reports will focus on assessment of impact on hardware performance, capital equipment, and operation costs.

\footnotetext{
*Work supported by the U. S. Department of Energy, Office of Buildings and Community Systems, under contract W-31-109-Eng-38.
} 


\subsection{Introduction}

Under sponsorship of the U.S. Department of Energy (DOE), Argonne National Laboratory (ANL) is developing improved energy transmission fluids for district heating and cooling (DHC) applications. This long-range program has as its objectives:

- To identify and develop high-performance thermal-hydraulic energy transmission fluids and the components to best use the fluids in DHC systems.

- To demonstrate that these fluids substantially reduce frictional losses and improve heat transfer, allowing use of smaller piping, pumps, heat exchangers, and storage tanks. These benefits will make DHC more viable and cost-competitive.

- To generate friction and heat transfer correlations and system performance information needed for design of improved DHC systems.

- To interact with industry and users to facilitate the above.

The DHC systems being studied by DOE are frequently composed of long runs of piping (sometimes miles in length) that convey the working fluid (in the heating or cooling mode) between the heat sources and sinks of the system. If the pressure drop or frictional losses associated with pumping these fluids and hence the pumping power can be reduced significantly, and if the heat transfer occurring at the heat exchangers and the energy per pound of circulating fluid can be increased, costs of operating these systems can be reduced. Cost reductions can also manifest themselves in the form of upfront capital equipment savings through the use of smaller pipes, pumps, heat exchangers, and storage tanks when new DHC system designs incorporating the improved energy transmission fluids are used. These fluids also promise to improve the performance of existing systems (i.e., through retrofitting).

In this report we shall consider the potential benefits of using phase change slurry and friction-reducing additives, either singly or in combination, in DHC systems. In Section 2 potential savings for new installations will be considered for the same delivered heating and cooling capacity. The savings will be discussed in terms of reduced sizes of the 
piping and equipment involved without attaching specific cost estimates for the components. In Section 3 potential increases in the heating/cooling capacity for a retrofitted existing system will be considered. Summary and conclusions are presented in Section 4.

The efforts to develop improved transmission fluids are based on an ANL feasibility study conducted in FY $-85^{1,2}$ that highlighted two concepts that hold considerable promise for improving the performance of DHC systems and on earlier ANL studies associated with the use of phase change slurries as the working fluid in thermal systems in general. 3,4

Both concepts are based on using special additives in DHC energy transmission fluids. The concepts can be used separately or combined to achieve maximum benefits. The individual concepts are:

- Addition of very low concentrations (20-200 wppm) of non-Newtonian materials to the appropriate carrier liquid to reduce frictional flow losses.

- Use of a pumpable phase change slurry composed of a liquid conveying particulates of a material with a high heat of fusion to enhance both bulk convective energy transport and heat transfer coefficients at heat exchanger surfaces. Two examples of candidate particulates are ice crystals (for cooling) and cross-linked, formstable, high-density polyethylene (for heating). Other materials are also being evaluated.

When the concepts are combined, the energy transmission fluid is composed of the appropriate phase change particles, friction-reducing additive, and carrier liquid.

A survey of the literature identifies additives that can reduce the frictional flow losses in DHC systems by $30-80 \%$ when used in conjunction with the proper solvents. The literature also shows that many frictionreducing additives do not enhance heat transfer and that in some cases heat transfer may be decreased. However, ANL has proposed other potential techniques to improve heat transfer in DHC systems. Some important background information associated with the concepts under development follows. 


\subsection{Friction Reduction}

The ANL scoping studies highlighted three general categories of additives that potentially can reduce pipe frictional losses when combined with the appropriate solvents. These substances are:

- high-molecular-weight linear polymers (i.e., polyethylene oxide [POLYOX], Separan, etc.)

- surfactants (i.e., alkaline metal soaps, etc.)

- large-aspect-ratio fibers or filaments (i.e., nylon, polyester, etc.)

All of these substances introduce highly elongated, semi-elastic filaments or fibers into a proper solvent that suppresses small-scale turbulence in a flow (i.e., TOMS Phenomenon), resulting in reduced frictional losses and reduced pumping power requirements.

The friction-reducing additives and the resulting improved working fluids need to have the following general characteristics for DHC applications:

- produce significant reduction in frictional losses under the thermal-hydraulic conditions encountered in DHC systems

- exhibit long life under continuous flow shear

- produce no significant negative influence on heat transfer equipment

- be economical

- produce no detrimental chemical interactions with system hardware, and if possible decrease corrosion

- raise no negative environmental or safety concerns

\subsection{Heat Transfer Enhancement}

Scoping studies were also performed to identify other concepts that could be of value in improving DHC system performance. Ways of improving heat transfer and energy storage within a DHC system were investigated. DOE and the Solar Energy Research Institute (SERI) have conducted several studies aimed at i) improving thermal energy storage by 
reducing the mass required to store thermal energy through use of phase change materials (PCM) with large latent heats, and at ii) improving insertion and extraction of energy from the storage medium through use of direct-contact heat exchange between the storage medium and the thermal energy transport fluid. These studies all use a captured static storage medium that is not recirculated in the thermal system. The more commonly used PCM fall into two categories. The solid-solid PCM have received considerable attention from SERI, and the solid-liquid PCM have been studied by the Energy Storage group of DOE Conservation.

In an earlier study conducted for DOE, Office of Buildings and Community Energy Systems, ANL presented a general overview of the preceding types of studies. 3,4 More importantly, the study highlighted the use of phase change slurries as entire system working fluids that could be used to simultaneously enhance the heat transfer at heat sources and sinks, the thermal energy transport density, and the ability to incorporate thermal energy storage into a system. For example, a 2- to 7-fold increase of the heat transfer coefficient for a liquid-solid interface over that for a single-phase heat transfer fluid (i.e., water) was shown to be possible.

One example of a type of PCM additive that might be used to form an enhanced heat transfer slurry in some district heating applications is partially cross-linked high-density polyethylene (X-HDPE). This material is formed by electron beam irradiation of polyethylene, which alters its molecular structure and renders it form stable. At $\sim 270^{\circ} \mathrm{F}, \mathrm{X}-\mathrm{HDPE}$ undergoes a phase transition that involves $70 \mathrm{Btu} / \mathrm{lbm}$. In the "molten" phase, individual particles in the slurry retain the shape they had in the solid phase and tend not to agglomerate or stick to heat transfer surfaces (providing that they have been sufficiently cross-linked). Cross-linking can also be explored for other materials with different melting points to meet the needs of various applications. In a similar manner, ice slush slurries are being explored for use with some district cooling applications.

Heat transfer at a surface is enhanced by the addition of particulate matter to a fluid through several mechanisms. For example, i) particle-particle and particle-wall interactions disrupt the laminar 
sublayer at the wall, ii) particle rotation in the shear zone adjacent to a surface produces microconvective stirring, and iii) the heat of fusion of the particle increases the heat capacity of the fluid, thus increasing the temperature gradient near a surface.

The ANL study also indicated that the desirable, high-volumetricparticle slurry loadings associated with the phase change slurries may produce modest increases in the pumping power required to move the slurry. However, recent ANL experiments have shown that the concept of using "slippery fluids" in DHC systems can be combined with the concept of using phase change slurries with enhanced heat transfer to produce greatly improved working fluids that exhibit frictional losses lower than that of the pure, single-phase carrier liquid. The improved working fluid is composed of the appropriate particulate PCM additive, friction-reducing additive, and carrier fluid. It should be noted that under some conditions, slurries without friction-reducing additives can require less pumping power than that for a pure carrier fluid.

\subsection{Concept Use Uncertainties}

The ANL study showed that important technical questions must be answered and additional information generated before the engineering feasibility of using friction-reducing additives and heat transfer enhancement in DHC systems can be demonstrated. In summary, these technical issues are:

- Some friction-reducing additives degrade fairly rapidly under continuous flow shear. To date no systematic, carefully controlled experiments have been conducted on friction-reducing additives to characterize and compare their tendencies for degradation. Because DHC systems are generally closed and working fluid recirculates to transport thermal energy, identification or development of long-life additives compatible with DHC thermal-hydraulic and operational conditions is essential.

- The limited studies on heat transfer show that accompanying the desired reduction in frictional losses is a reduction in heat transfer between fluid and wall. Because the DHC systems 
have heat sources and sinks at which heat transfer takes place, quantification of reduction in heat transfer coefficients and assessment of the impact on overall performance of heat exchange equipment is essential. No data are available for heat transfer in commonly used heat exchangers for operation with friction-reducing solutions.

- The feasibility of combining friction-reducing additives with a heat-transfer-enhancing slurry must be studied and appropriate substances identified that are compatible with DHC applications. The practicality of using slurry flows must also be explored relative to such matters as pumpability, valve controllability, flow blockage, sedimentation, and compatibility with existing DHC equipment designs.

- Studies have shown that solvent chemistry and contaminants can strongly influence the frictional, heat transfer, and degradation characteristics of friction-reducing additives. The roles of chemistry and contaminants are not well understood, and in many cases what actually constitutes a contaminant is not clear. Because water quality in DHC systems can vary considerably between installations, the influence of such factors as $\mathrm{pH}$, hardness, rust, dissolved gas content, and other organic and inorganic contaminants must be assessed.

- The mechanisms and modeling parameters controlling the friction, heat transfer (for both friction-reducing additives and slurries), and degradation rates in the improved working fluids are not understood in any generality. Hence, reliable correlations are virtually nonexistent. The limited understanding of scale-up procedures from reduced-scale experiments to prototype-size DHC applications will hinder predictions of prototype performance.

- No data were found on heat transfer behavior of frictionreducing additives or slurries or on their degradation tendencies in flow through elbows, expansions, contractions, valves, rough wall pipes, pumps, and heat exchangers. Such data are needed to assess the performance of DHC systems. 


\subsection{Program Overview}

The ANL program for development of optimal energy transmission fluids is a long-range program consisting of two phases. The main components of each phase are described here.

Phase $I$ is directed at identifying and determining the characteristics of additives to transmission fluids that satisfy the requirements of $\mathrm{DHC}$ applications (for heating and cooling). This phase will focus mainly on identifying, through carefully conducted experiments, friction-reducing additives that are "robust" and sufficiently nondegradable and also phase change materials that can improve heat transfer. The additives are being screened for compatibility with the conditions encountered in DHC distribution systems and their ability to significantly reduce pipe friction losses and improve heat transfer. Promising additives of the linear polymer, surfactant, and filament types are undergoing testing in ANL's Slurry Heat Transfer Test Facility (SHTE). Because the impact of additive degradation rate on both friction and heat transfer must be characterized, the test apparatus is a pumped, closed-recirculatory-loop system with a measurement section in which both heat transfer and pressure drop are observed as functions of time. Ultimately, all friction-reducing additives will undergo final testing in the ANL system to allow comparison of all additives on an equal basis. Ice slurries will also be tested to explore the feasibility of their use for cooling systems. Various aspects of forming and pumping ice slurries are being explored. Phase change materials such as X-HDPE and wax are being explored for heating applications. Other phase change materials suitable for different system operation temperatures will also be sought. The flow and heat transfer characteristics of the combined-concepts fluids are being studied because of their potential for achieving optimal energy transmission. Finally, the concepts under development are being comprehensively assessed for their impact upon DHC applications.

In Phase II the additives identified and developed under Phase I will be tested in a reduced-scale DHC system simulator at ANL. The interactions of the additives with actual pumps, heat exchangers, piping, and instrumentation encountered in DHC applications will be studied under 
carefully controlled and easily changed parametric conditions (both for existing types of systems and improved designs suggested by the current study). Equipment from various manufacturers is being made available to ANL to achieve this goal. Flow and heat transfer correlations will be generated for the various components under DHC operating conditions, and the influence of additive concentration, water chemistry, and temperature on performance will be assessed. Depending on results from early work in Phase II, components yielding better performance with the new fluids may need to be developed. For example, heat exchanger design can be optimized for operation with phase change slurries (smaller and generically less prone to flow blockage). Also in this phase, field studies will document improved performance of an existing DHC system(s) with the new fluids. Considerable effort will also be directed toward working with DHC equipment manufacturers and installers as well as with the suppliers of the additives to develop a handbook giving guidelines for using the concepts and information that have been developed.

\subsection{Preliminary Proof-of-Concept Results}

Proof-of-concept experiments have been conducted in the SHTF at ANL. A schematic drawing of the test facility is shown in Fig. 1. The facility has recently been expanded to include a test apparatus for testing degradation of friction-reducing solutions in a closed system with recirculating flow. The major components of the test facility are: a 3000-L (800-gal) supply tank, a 3000-L storage tank, a 380-L (100-gal) weighing tank, two progressing-cavity slurry pumps with pumping capacities of $0.063-3.786 \mathrm{~L} / \mathrm{s}(1-60 \mathrm{gpm})$, and two test sections. The test sections are straight tubes approximately $6 \mathrm{~m}(20 \mathrm{ft})$ long. One test section is a clear plastic tube of diameter $25.80 \mathrm{~mm}(1-1 / 64 \mathrm{in.})$. The other test section is a stainless steel heat transfer tube of diameter $23.98 \mathrm{~mm}(0.944$ in.). For heat transfer experiments, two DC electrical power supplies connected in series can supply up to $60 \mathrm{~kW}$ to the stainless steel test section to simulate a constant wall heat flux boundary condition. Furthermore, the supply tank has electrical heaters and heating coils for preheating the slurry, and the storage tank contains cooling coils for cooling the discharged slurry. An injection tap is placed at the tube wall 
approximately $3 \mathrm{~m}$ (10 ft) upstream of the first pressure tap in order to ensure adequate mixing of the friction-reducing additive solution with test fluids in the test section.

The instrumentation for the pressure drop and mass flow measurements consists of two pressure taps, a pressure transducer, a weighing tank, and a data logger. The pressure taps are placed at the tube wall in the fully developed flow region of the plastic test section. The distance between the two pressure taps is $3.29 \mathrm{~m}(10.8 \mathrm{ft})$. A 68.9-kPa differential pressure transducer measures the pressure drop between the two pressure taps. Thermocouples inserted in the supply tank measure the slurry temperature in the tank. All test data, including pressure drop, mass flow, and temperature, are recorded by a Fluke Model 2285B data logger.

The experiments were performed for a range of flow rates between 0 and $148 \mathrm{~kg} / \mathrm{min}(326 \mathrm{lb} / \mathrm{min})$. The particle volumetric loading was varied from 0 to $35 \%$ to determine the effect of particle loading on pressure drop and heat transfer. The particles used in this study were X-HDPE particles of $3.2 \mathrm{~mm}$ ( $1 / 8 \mathrm{in.})$ diameter. In addition to the tests with pure water and a slurry of water and X-HDPE particles, tests were conducted both with water and a friction-reducing additive and with a slurry of water and XHDPE particles plus a friction-reducing additive. The friction-reducing additive was a solution of POLYOX WSR-301, an ethylene oxide polymer manufactured by Union Carbide, with deionized water as the solvent. The solution was mixed initially to a concentration of $2000 \mathrm{wppm}$ and injected into a pipe flow through the injection tap. The final concentrations of the additive were varied from 30 to $200 \mathrm{wppm}$, depending on the flow rates of the test fluids. The maximum flow rate of $148 \mathrm{~kg} / \mathrm{min}$ yielded the minimum additive concentration of $30 \mathrm{wppm}$. Although the additives tested in the present tests are not optimal for DHC applications, their initial testing quickly generated data to support proposed concepts and serve as a reference base for comparing results from future work directed at identifying and developing optimal energy transmission fluids for DHC.

The four fluids tested are:

1. Pure water (reference case); 
2. A slurry of pure water and solid particles of X-HDPE (volumetric loadings to $35 \%$ );

3. Pure water with a friction-reducing additive called POLYOX (concentration 30-200 wppm); and

4. A slurry of pure water, X-HDPE particles at $15 \%$ loading, and POLYOX (30-200 wppm).

The heat transfer data are reported for a Type 2 fluid for nonphase-change conditions. The experimental data on the pressure drop for the four fluids are shown in Fig. 2a. The pressure drop data for pure water are in excellent agreement with well-established friction laws for turbulent pipe flow such as the Karman-Nikuradse law of friction. The pressure drop associated with slurries of 15,20 , and $25 \%$ loadings of XHDPE exhibits a negligible increase over that of pure water. This pressure drop behavior is quite different from that of such slurries as coal-water mixtures, for which the pressure drop increase is significant. The negligible density difference between water and X-HDPE particles could be responsible for the negligible pressure drop increase for $X-H D P E$ slurries. Figure $2 \mathrm{a}$ also shows that the addition of the friction-reducing additive POLYOX to water drastically reduces the pipe flow pressure drop relative to that measured with pure water. Furthermore, the addition of the friction-reducing additive to an X-HDPE slurry of $15 \%$ loading is nearly as effective in reducing slurry pressure drop as is its addition to pure water.

Pressure drop data for a 15\% loading of X-HDPE slurry, for water with POLYOX, and for a 15\% loading of X-HDPE slurry with POLYOX were replotted in Fig. $2 \mathrm{~b}$ to show the percent pressure drop change over water [i.e., the ratio between the frictional pressure drop for the slurry flow and the frictional pressure drop for related single-phase (pure water) flow]. Some very interesting trends in percent pressure drop were observed for a slurry without POLYOX. For example, at very low mass flows the pressure drop penalty relative to pure water increased by $7 \%$. Since the $X$ HDPE particles are slightly less dense than water, this is probably due to stratified flows in which the particles concentrate toward the top of the pipe, causing nonuniform particle distributions across the pipe. Visual observation and video recordings of flow patterns confirmed partial 
stratification at low flow rate. In the stratified region, particles near the wall may cause increased friction, resulting in increased velocity and pressure drop. At high flow rate, the particles were uniformly distributed over the flow field because of strong turbulence, and the pressure drop penalty decreased, resulting in negligible pressure drop increase over that of pure water. This trend in percent pressure drop of a buoyant particle slurry is expected to be different from that of a neutrally buoyant particle slurry and to vary for different types of slurries.

For flows with the friction-reducing additive, the mass flow rate of pure water or slurry is an important parameter in determining the effectiveness of the additive in reducing pressure drop. At low mass flow rates the friction-reducing additive is twice as effective for pure water as it is for slurry (see Fig. $2 b$ ). However, at high mass flow rates the percent pressure drop reduction due to the friction-reducing additive is almost identical for pure water and slurry. The maximum value of the pressure drop reduction is approximately 70\%. The mean concentration of POLYOX in the pipe flow is 200 wppm at the minimum mass flow rate and 30 wppm at the maximum mass flow rate.

The slurry heat transfer data, without phase change, for various particle loadings are plotted in Fig. 3. The nondimensional heat transfer Nusselt number $(\mathrm{Nu})$, which is directly proportional to the wall-slurry heat transfer coefficient, is plotted versus a modified Reynolds number (Re) that is based on an effective slurry viscosity. For the slurries $(\phi>0)$, $\mathrm{Nu}$ increases with increased particle loading $(\phi)$. Significant $\mathrm{Nu}$ enhancement is observed. For $\mathrm{Re}=4 \times 10^{4}$ with $\phi=30 \%$, $\mathrm{Nu}$ is increased by a factor of 2.5 over that for pure water. Further analysis of the slurry data and additional experiments have been scheduled to explore melting/solidification and to extend the range of the data on volumetric loading and particle size in order to more fully explore the effects of these parameters on heat transfer and pressure drop. Additional parametric representations are being explored to ascertain the best way of presenting this type of data. 
In conclusion, a series of pressure drop and heat transfer tests have been conducted for pure water and X-HDPE slurry flows with and without a friction-reducing additive. These tests have generated preliminary proof-of-concept information that supports the use of advanced energy transmission fluids for DHC applications:

- The highly loaded slurries envisioned for DHC applications will not necessitate pumping power requirements much greater than those currently encountered with DHC systems using pure water.

- A friction-reducing additive can be successfully combined with a phase change slurry or pure water for significant pressure drop reduction in DHC systems.

- Slurries exhibit increased wall-fluid heat transfer as compared to a pure, single-phase energy transmission fluid.

\subsection{Potential Benefits for New Installations}

In this section we shall consider the benefits to new DHC installations of using the phase change and friction reduction concepts. These benefits appear in the form of smaller piping sizes, reduced pumping power, and reduced heat losses. The projections represent best estimates and extrapolations based on available information, which is clearly scanty and inadequate for firm performance calculations. Accordingly, the discussion is offered here as the motivation for more research and development in this potentially fruitful area of endeavor. It is not our intention to ignore the potential problems associated with this new technology. Some of the potential concept implementation difficulties were discussed in Section 1.3 .

A generic, simplified DHC system is shown schematically in Fig. 4. Major components are a source heat exchanger, a heat (or cold) storage facility, a pump, a distribution system consisting of a considerable amount of piping, and a number of load heat exchangers where heating and cooling loads are met. 


\subsection{General Benefits}

Some of the benefits of using phase change slurries and frictionreducing additives can be explored without referring to specific heating or cooling applications. These general benefits will be discussed first.

\subsubsection{Reduction of Flow Rate and Pumping Power Requirements Due to the Use of Phase Change Slurries}

The main advantage in using a phase change slurry in DHC is the increased heat capacity of the heat transfer fluid due to the latent heat $(\lambda)$ of the particulate phase change material. This increased heat capacity allows a reduced fluid flow rate to satisfy a given load. 3,4 The heat capacity for a sensible-heat system (e.g., a DHC system using singlephase water as the energy transmission fluid) is $\dot{M}_{0} C_{0} \Delta T^{\prime}$ and that for a phase change slurry (e.g., water plus particles of X-HDPE or ice crystal) is $\dot{M}_{p c}\left(\phi \lambda+C_{p c} \Delta T\right)$, where $\phi$ is the mass fraction of the phase change material and $C_{p c}$ is the specific heat of the slurry mixture (see Nomenclature). Hence, the ratio of mass flows between a slurry undergoing phase change and a sensible-heat energy transmission fluid for the same energycarrying capacity is

$$
\frac{\dot{M}_{p c}}{\dot{M}_{0}}=\left(\frac{C_{p c}}{C_{0}}+\frac{\phi \lambda}{C_{0} \Delta T}\right)^{-1} \text {. }
$$

To illustrate calculation of the mass flow reduction and associated savings in pressure drop and pumping power, we will consider a slurry of water with phase change material of comparable density and $\phi=30 \%$. Also it is assumed that $\Delta \mathrm{T}^{\prime}=\Delta \mathrm{T}$ and $\mathrm{C}_{\mathrm{pc}}=\mathrm{C}_{\mathrm{o}}$. The baseline system for comparison is a sensible-heat (i.e., single-phase) water system, with $C_{0}=1 \mathrm{Btu} / 1 \mathrm{~b}^{\circ} \mathrm{F}$. The results are shown in $\mathrm{Fig} .5$. The latent heat for ice, a candidate phase change material for cooling applications, is 143 Btu/lb. The latent heats for two candidate materials for heating applications (X-HDPE and wax at 72 and $85.5 \mathrm{Btu} / \mathrm{lb}$, respectively) are both in the vicinity of $80 \mathrm{Btu} / \mathrm{lb}$. Significant reductions in mass flow rate are clearly possible, especially at the lower temperature differences. 
The use of phase change slurries also leads to potential reductions of pressure drop, which is strongly dependent on flow rate. Hence, satisfying a given heating or cooling load with a reduced flow rate leads directly to a reduced pressure drop, provided that adding particles doesn't increase the pressure drop. Existing data show that as long as the density difference between carrier and particles is small and the volume fraction of the solids is not excessive, the pressure drop for a slurry system is not significantly greater than for single-phase systems at comparable flows. A partial explanation for this may be the friction reduction previously reported for dilute slurries. 5 As was mentioned in Section 1.5, ANL data confirm this behavior for slurries and further highlight the fact that friction-reducing additives can be used with slurries to reduce pressure drop significantly below that of a single-phase energy transport fluid.

For the present estimate, the slurry pressure drop is assumed to behave as would a single-phase Newtonian fluid, with the pressure drop $(\Delta p)$ obeying the pipe friction formula

$$
\Delta p=f \frac{L}{D} \rho \frac{u^{2}}{2}
$$

where

$$
f=0.316\left(\frac{u D}{v}\right)^{-.25} .
$$

Accordingly, the ratio of pressure drop for the phase change system to that for the baseline conventional water system is

$$
\frac{\Delta \mathrm{p}_{\mathrm{pc}}}{\Delta \mathrm{p}_{\mathrm{o}}}=\left(\frac{\dot{\mathrm{M}}_{\mathrm{pc}}}{\dot{\mathrm{M}}_{\mathrm{o}}}\right)^{1.75} \text {. }
$$

The pumping power (W) associated with moving the fluids through a pipe is proportional to the product of the flow rate and the pressure drop. Hence,

$$
\frac{\mathrm{W}_{\mathrm{pc}}}{\mathrm{W}_{\mathrm{o}}}=\left(\frac{\dot{\mathrm{M}}_{\mathrm{pc}}}{\dot{\mathrm{M}}_{\mathrm{o}}}\right)^{2.75} \text {. }
$$


These relationships are plotted in Figs. 6 and 7 , respectively. The reductions in pressure drop and pumping power allowed by the use of phase change slurries are even more dramatic than is the reduction of the mass flow rate.

Figures 5,6 , and 7 differ from similar figures in Refs. 3 and 4 in that the previous curves were based on source-to-load temperature differences whereas the present results are presented on the basis of the temperature change in the fluid. Furthermore, the earlier estimate employed a two-fold slurry pressure drop penalty over that of pure carrier fluid. In view of a more thorough survey of the literature on slurry pressure drop and the recent experiments conducted at ANL, this penalty was judged to be unnecessary in the present estimate of the behavior of the slurries envisioned for DHC applications.

\subsubsection{Reduction of Storage Tank Volume and Heat Loss Due to the Use of Phase Change Slurries}

The increased heat capacity of the phase change slurry compared to that of a sensible-heat energy transmision fluid also leads to reduced energy storage tank volume. For the same energy storage capacity, the ratio of the storage tank volumes is given by an equation similar to Eq. (1).

$$
\frac{V_{p c}}{V_{0}}=\frac{\rho_{0}}{\rho_{p c}}\left(\frac{C_{p c}}{C_{o}}+\frac{\phi \lambda}{C_{o} \Delta T}\right)^{-1} .
$$

The solids fraction $\phi$ in the storage tank can be higher than that in the circulating slurry, 3,4 resulting in even greater energy storage capacity. The conservative assumption that $\phi=0.6$, together with the previous assumption that $C_{p c}=C_{0}=1$, yields the ratios of storage volumes shown in Fig. 8 .

With a smaller storage tank, the heat loss $\mathrm{Q}_{\mathrm{L}}$ is also reduced. $Q_{L}$ is proportional to the surface area and hence proportional to the $2 / 3$ power of the volume. This relationship is shown in Fig. 9 . 


\subsubsection{Heat Transfer Enhancement and Heat Exchanger Size}

Reductions Due to the Use of Phase Change Slurries

Evidence presented by Sohn and Chen, 6,7 Kasza and Chen, 3,4 and Chen and Chen ${ }^{8}$ suggests that in a phase change slurry the heat transfer coefficient may be increased by one of two mechanisms: i) the stirring effect of the particles, or $i i)$ the increased heat capacity associated with the latent heat of the phase change particles. Estimates of the potential enhancement of the heat transfer coefficient due to the stirring effect (i.e., for a slurry without phase change) are shown in Table 1. Heat transfer enhancement due to increased heat capacity, under the assumption of local phase equilibrium, was estimated by the following relationship. 8

$$
\frac{h_{p c}}{h_{0}}=\left(\phi \frac{\lambda}{c \Delta T}+1\right)^{1 / 3}
$$

The results are plotted in Fig. 10. The potential enhancement is particularly significant at low temperature differences.

Although it is not clear whether these two mechanisms can be realized simultaneously in practice, with a judicious choice of materials some enhancement of the heat transfer coefficient, say by a factor of two or three, might be realizable. We are conducting experiments at ANL to explore these enhancement mechanisms, whose realization would lead to a corresponding reduction of the size, and hence the cost, of the heat exchangers.

\subsubsection{Pressure Drop and Pumping Power Reductions Due to Friction-Reducing Additives}

Friction reduction resulting from adding minute amounts of a polymer, surfactant or fibrous material to a liquid has been discussed in the Introduction.

For the present assessment of impact on DHC systems, a simplified correlation for the asymptotic friction factor $\left(f_{f r}\right)$ of turbulent water pipe flow with a non-Newtonian additive will be used:

$$
f_{f r}=2.26(R e)^{-0.56}
$$


Equation 8 is not a universally valid correlation; it assumes that adequate amounts of friction-reducing additive have been added to the liquid (i.e., 50-200 ppm). This factor can be compared with the friction factor for turbulent Newtonian fluid (i.e., pure water) pipe flow previously given in Eq. (3).

For a given flow rate, the ratio of pressure drops or pumping powers between the friction-reduced pipe flow and the pure water flow is the ratio of the friction coefficients. Hence, from Eqs. (8) and (3),

$$
\frac{\Delta p_{f r}}{\Delta p_{o}}=\frac{W_{f r}}{W_{o}}=7.15 \mathrm{Re}^{-0.31} .
$$

This relationship is shown in Fig. 11. Significant reductions in pressure drop and pumping power are indicated.

Certain types of friction-reducing additives cause a reduction of the heat transfer coefficient. The phenomenon is not well understood and in any case does not necessarily greatly diminish the performance of the heat transport system as a whole. For example, in water-air heat exchange systems, the air-side resistance often dominates the overall performance. An appreciable reduction of the heat transfer coefficient on the liquid side would have only a minor overall effect. Furthermore, the heat transfer reduction may be quite insignificant or totally absent under certain ranges of operating conditions (e.g., laminar flow) or with certain classes of friction-reducing additives, such as surfactants. Proper system design may thus maximize the friction reduction benefits while minimizing the heat transfer reduction effects.

\subsection{Specific Benefits for District Cooling Applications}

In this section we shall consider the benefits that can be effected in district cooling applications by the use of i) phase-change slurry alone, ii) friction-reducing additive alone, or iii) a combination of both. The phase change slurry that we have chosen as an example is an ice slush slurry with $30 \%$ circulating solids by weight. In the storage 
tank, however, the concentration of solids will be increased to $60 \%$ to take full advantage of the large heat capacity of ice.

Identifying a single representative conventional chilled-water cooling system for comparison is somewhat difficult. American practice in building cooling uses relatively small temperature rises of about $10^{\circ} \mathrm{F}$, sometimes even as little as $5^{\circ} \mathrm{F}$. This tendency reflects the desire to maximize chiller temperature and hence the refrigeration coefficient of performance (COP), with relatively low distribution costs. In contrast, the standard European practice that uses chilled water for district cooling employs a $\Delta \mathrm{T}$ of about $20^{\circ} \mathrm{F}$ in the interest of a higher heat capacity and hence the reduced initial and operating costs associated with long-distance distribution. To reflect these diverse practices, comparisons of the relative flow rates and storage tank volumes will be carried out for three different chilled water temperature ranges: $40^{\circ} \mathrm{F}$ to $45^{\circ} \mathrm{F}, 38^{\circ}$ to $48^{\circ} \mathrm{F}$, and $35^{\circ}$ to $55^{\circ} \mathrm{F}$. Subsequent comparisons of pressure drop and pumping power will be made with a reference system at $38-48^{\circ} \mathrm{F}$, representing the median of the three systems.

\subsubsection{Heat Capacity Increases and Flow Rate and Storage Tank Volume Reductions Due to Phase Change Slurry}

A major benefit of the use of phase change slurry is the increased heat capacity due to the latent heat of fusion. As a consequence, the flow rate of the energy transport medium can be significantly reduced. In addition, there is an associated reduction in the volume of the cold storage tank that is needed for load leveling. These savings, computed from Eqs. (1) and (6), are shown in Fig. 12. The two entries for the storage volume for ice slush slurry are based on $30 \%$ and $60 \%$ tank loading. While the circulating slurry is limited to a modest solids loading to maintain fluidity (in the range of $30 \%$, with the actual limits being explored), such a limit does not exist for the storage tank, where a high solids loading will take full advantage of the latent heat.

Figure 12 shows that the flow rate and tank volume reductions can be considerable. The $30 \%$ ice slush slurry requires only $18 \%$ of the flow rate and tank volume of the $38-48^{\circ} \mathrm{F}$ chilled water system, and $9 \%$ 
of the flow rate and tank volume of the $40-45^{\circ} \mathrm{F}$ chilled water system. Even more dramatic is the storage tank reduction with a loading of $60 \%$ ice, which requires only $10 \%$ the volume of the $38-48^{\circ} \mathrm{F}$ system and $5 \%$ of the volume of the $40-45^{\circ} \mathrm{F}$ system.

In conjunction with the reduction in storage tank volume is an accompanying reduction of the heat gain from the ambient, which represents a loss. For this comparison, the heat gain is assumed to be proportional to the surface area and to the temperature difference between a $75^{\circ} \mathrm{F}$ ambient and the lowest temperature in the system. The surface area is assumed to be proportional to the $2 / 3$ power of the volume. The use of the relatively low ambient temperature of $75^{\circ} \mathrm{F}$ rather than a typically higher summer ambient temperature slightly penalizes the lower-temperature chilled water systems, including the ice slush storage system, relative to the high-temperature systems. Hence, the benefit estimates are slightly conservative.

The savings in heat gain are shown in Fig. 13. The $60 \%$ ice slush storage system has a heat gain that is only $20 \%$ of that of the $38-48^{\circ} \mathrm{F}$ chilled water system.

\subsubsection{Pressure Drop and Pumping Power Reductions at Constant Pipe Diameter}

\subsubsection{Improvements Due to Friction Reduction Alone}

As was discussed previously, the potential benefit of using friction-reducing additives is a function of the pipe flow Reynolds number, as is shown in Fig. 11 for pressure drop reduction. This relationship is also shown in Fig. 14, for comparison with phase change and the combined concepts to be discussed below. Because pumping power is equal to the product of flow rate and pressure drop, for the friction reduction concept alone the pumping power reduction is equal to the reduction of the pressure drop. This is shown in Fig. 15. All comparisons are for $\mathrm{Re}>2300$, which is turbulent pipe flow, because friction reduction only occurs for turbulent flow.

Two additional scales are shown at the tops of Figs. 14 and 15 in terms of practical units. For constant fluid 
properties, the Reynolds number is proportional to the product UD of the velocity and the diameter or the ratio of the flow rate and the diameter $(\dot{Q} / D)$. The kinematic viscosity assumed for these conversions is $1.79(10)^{-6} \mathrm{~m}^{2} / \mathrm{s}$, corresponding to water at $0^{\circ} \mathrm{C}$. The viscosity variation with temperature is quite significant near the freezing point; therefore, these scales are intended for semiquantitative comparison only.

\subsubsection{Improvements Due to Phase Change Slurry Alone}

A significant reduction of the pressure drop in the piping system and an accompanying drop in the pumping power are associated with the reduction of coolant flow rate achieved by using a phase change slurry. Existing data on the pressure drop of slurries, including data obtained at $\mathrm{ANL},{ }^{9}$ suggest that solids suspensions in the $30 \%$ loading range incur little or no penalty in pressure drop as compared to single-phase fluids of comparable flow rate. Accordingly, the relationships for single-phase Newtonian fluids between pressure drop, pumping power and flow rate are simply

$$
\begin{aligned}
& \Delta p \propto \frac{1}{2} \rho u^{2} \propto \dot{Q}^{1.75} / D^{4.75} \\
& W \propto \dot{Q} \Delta p \propto \dot{Q}^{2.75} / D^{4.75}
\end{aligned}
$$

where the friction factor of Eq. (3) has been incorporated.

The relative pressure drop and pumping power of the ice slush slurry as compared to those of the $38-45^{\circ} \mathrm{F}$ chilled water system are shown in Figs. 14 and 15. To avoid clutter, the comparisons with the $40-45^{\circ} \mathrm{F}$ and $35-55^{\circ} \mathrm{F}$ chilled water systems are not shown. However, calculations have shown that in comparison with the $40-45^{\circ} \mathrm{F}$ water system, the pressure drop and pumping power ratios would be about 3.4-fold and 6.7fold smaller, respectively, than those shown in Figs. 14 and 15 . The pressure drop and power ratios relative to the $35^{\circ}-55^{\circ} \mathrm{F}$ system would be about 3.4-fold and 6.7-fold larger, respectively, than those shown in Figs. 14 and 15. The benefits of using a phase change ice slurry are dramatic in any case. 


\subsubsection{Improvements Due to Combination of Friction Reduction and Phase Change}

The greatest potential improvement would be obtained when the phase change slurry concept and the friction reduction concept are used simultaneously. Little information is available on the influence of friction-reducing additives on the pressure drop of slurry systems. ANL has generated some preliminary data that suggest that the presence of particulates does not adversely affect friction reduction. 9 Our comparisons are made in the spirit of exploring the potential benefit to be accrued and are based on the assumption that the particulates exert no adverse influence on friction reduction (i.e., both phenomena exert their influence independently of one another). Figures 14 and 15 show the influence of the combined concepts on reductions in pressure drop and pumping power.

\subsubsection{Pipe Size Reductions and Associated Savings}

Another potential benefit of using friction-reducing additives and phase change slurries is reduction of pipe sizes and the associated savings. This is in contrast to the comparisons in Figs. 14 and 15, which are for constant pipe diameter. This benefit can be viewed in two ways. We can examine the pipe size reductions if the system pressure drop remains constant. This, however, does not represent ultimate savings. Because the flow rate is reduced by the use of phase change slurries, the system can tolerate a higher pressure drop without additional power consumption. Therefore, a more favorable comparison of the influence on pipe size can be made on the basis of constant pumping power.

The cost of piping depends on both the material cost and the installation cost, neither of which is a linear function of pipe size. Under certain circumstances, a small reduction in pipe size may lead to a dramatic reduction in cost. For example, the number of persons involved in laying pipes is often governed by union contracts. The decrease from one size to the next smaller size may lead to a much smaller personnel requirement with an accompanying step-wise decrease in labor cost. 
In the case of friction-reducing additives, the reduction in pipe diameter is made possible by the increased flow velocities permitted if the pressure drop remains the same as that of the fluid without the additives. In the case of phase change slurry, the smaller pipe size is allowed largely by the reduced flow rate requirement associated with satisfying the same thermal load. The pipe diameter reductions obtained by using either concept alone or both combined are shown in Fig. 16. For the ice slush slurry the basis for comparison is a loading of $30 \%$ by weight of ice in water.

The reductions of pipe diameter are accompanied by large reductions in the fluid inventory. This is shown in Fig. 17. Similar comparisons of pipe size and fluid inventory under the assumption of constant power are shown in Figs. 18 and 19. The trends are similar to those for the constant pressure drop.

\subsection{Specific Benefits for District Heating Applications}

In this section, specific examples are presented of the benefits of using advanced energy transmission fluids with friction-reducing additives and/or phase change slurries, over a conventional heating system with hot water as the heat transmission fluid. Because of the diversity of heating systems, two different "benchmark systems" will serve as bases for comparison.

In the U.S., heating systems for large buildings normally use nonpressurized water with a typical supply temperature of $180^{\circ} \mathrm{F}$ and a return differential of $20^{\circ} \mathrm{F}$. If a district heating system is viewed as an extension of a heating system for a large building, these parameters might be typical for a nonpressurized system. However, for our benchmark system, the differential is increased to $30^{\circ} \mathrm{F}$ to obtain greater capacity that will offset the potentially greater distribution cost of a district heating system versus a building heating system. This benchmark system will be referred to as the "nonpressurized water system" (NPW); it has supply and return temperatures of $180^{\circ} \mathrm{F}$ and $150^{\circ} \mathrm{F}$, respectively.

European countries are more advanced than the U.S. In the use of district heating systems. They commonly use pressurized water at a supply 
temperature of $230-260^{\circ} \mathrm{F}$ and a return temperature of $122-158^{\circ} \mathrm{F}$. The higher temperature differences result in greater heat capacities per pound of fluid than in American practice. These temperatures are also more compatible with the requirements of cogeneration and offer economies for total energy usage. A benchmark system based on these conditions will be referred to as the "pressurized water system" (PW); it has supply and return temperatures of $248^{\circ} \mathrm{F}$ and $140^{\circ} \mathrm{F}$, respectively.

The selection of an advanced energy transmission fluid to compare for these two benchmark systems depends primarily on the choice of phase change materials that can operate in the same temperature ranges. For a slurry to operate in the $150-180^{\circ} \mathrm{F}$ range of the NPW system, a candidate phase change material is any of many waxes with melting points spanning the $150-180^{\circ} \mathrm{F}$ range and latent heat in the vicinity of $80-90 \mathrm{Btu} / \mathrm{lb}$. The calculations will be based on a melting point of $157^{\circ} \mathrm{F}$ and a latent heat of $85.5 \mathrm{Btu} / \mathrm{lb}$, with the wax suspended in water. These values are typical of many waxes and specific reference to a particular wax need not be made.

The calculations for a slurry operating in the temperature range of the PW system will be based on a mixture of water and X-HDPE. This choice is based on the latter's particularly desirable property of form stability, which results from partial cross-linking, so that the material maintains its original shape even when the bulk of the material has changed into the liquid phase. Therefore, the globules of the essentially molten phase are prevented from coalescing into a continuous phase and destroying the slurry. At present, the only technical data available for cross-linked polymers are for X-HDPE, which has a melting point of $270^{\circ} \mathrm{F}$ and a latent heat of $72 \mathrm{Btu} / \mathrm{lb}$. The melting point is slightly higher than the $250^{\circ} \mathrm{F}$ parameter of the pressurized water system. The comparisons performed here use this material in the spirit of a sample calculation, assuming that the slightly higher melting point does not have a significantly adverse influence on the system. After further development, the concept of partial cross-1inking may well be applicable to polyethylene of lower molecular weight or to other plastics with lower melting points, allowing tailoring of a material to a specific temperature range. 


\subsubsection{Heat Capacity Increases}

Heat capacities per pound of working fluid are shown in

Table 2. For these comparisons the circulating slurries are assumed to have $30 \%$ phase change material by mass. The wax and water system has $74 \%$ greater heat capacity per pound of fluid than the conventional

nonpressurized hot water system. In addition, the conventional pressurized water system has a 3.6-fold higher heat capacity than the conventional nonpressurized water system. Even greater heat capacity (4.6-fold) is associated with the $\mathrm{X}-\mathrm{HDPE}$ and water mixture.

Corresponding savings in storage tank volume are shown in Column 2 of Table 2. For this calculation, the concept of increased loading at storage, introduced by Kasza and Chen, 3,4 was used. The mass fraction of the phase change material in the storage tank is assumed to be increased to $60 \%$, because fluidity is not a requirement there. This assumption results in even greater heat capacity. For example, the storage tank volume of a pressurized X-HDPE and water system is only $21 \%$ of that of a single-phase low-pressure water system.

The relative heat losses of the various systems are shown in Column 3 of Table 2. For this calculation the heat loss is assumed to be proportional both to the temperature difference between the tank and ambient $\left(20^{\circ} \mathrm{F}\right)$ and to the surface area, which is assumed to vary as the $2 / 3$ power of the volume. Heat loss reduction is significant, but less dramatic than the reduction in volume, partly because of the higher operating temperature of the pressurized systems.

\subsubsection{Pressure Drop and Pumping Power Reductions for Constant Pipe Diameter}

The reduction in pressure drop and pumping power with constant pipe diameter both for the nonpressurized wax and water system versus the nonpressurized water system, and for the X-HDPE and water system versus the pressurized water system, are shown in Figs. 20 and 21 . The proposed systems generally have pressure drops and pumping powers that are fractions of those for comparable conventional hot water heating systems. 


\subsubsection{Pipe Size Reduction and Associated Savings for Constant Pressure Drop or Constant Power}

The reduction of pipe size and the associated reduction of fluid inventory for the assumption of either constant pressure drop or constant power are shown in Figs. 22-27 for the advanced fluids in heating systems.

The potential reduction of pipe diameter allowed by the use of either phase change or friction-reducing additives or a combination of the two, under the condition of constant system pressure drop, is shown in Fig. 22. The benefit of using phase change alone is not a function of the system Reynolds number. This benefit amounts to a $7-18 \%$ reduction of the pipe size. On the other hand, the benefits from the use of frictionreducing additives depend on the benchmark Reynolds number $\mathrm{Re}_{\mathrm{O}}$. The greatest benefits are derived when $R_{0}$ is large; for $R_{o}$ values ranging from $10^{6}$ to $10^{7}$, roughly a two-fold reduction of pipe size is potentially possible.

The cost of piping is roughly proportional to the volume, which is, in turn, proportional to the square of the pipe diameter. In addition, handling problems for large pipes may lead to step changes in installation costs when the pipe sizes exceed certain critical values. Thus, the reductions in pipe size shown in Fig. 22 could lead to very significant reductions in materials and installation costs.

Associated with the reduction in pipe size is a reduction in the fluid inventory contained in the piping system. This is shown in Fig. 23. The cost of the fluid inventory depends on the fluid used. Even with water as the working fluid, the cost of the fluid inventory may be significant, because some purification and additives may be required to prevent fouling and corrosion.

The cost benefits (or penalties) for the phase change slurry system versus the benchmark system can only be assessed when precise cost data are available. On the other hand, the fluid inventory reduction of the friction-reduced system is quite significant, as much as $75 \%$ at high Reynolds numbers, because typically only a minute amount of the additive produces the desired effect. Furthermore, systems using combined phase change and friction reduction may require as 1 ittle as $17 \%$ of the benchmark 
fluid inventory. Such reductions can clearly minimize the cost impact of the phase change material contained in the slurry.

Figures 24 and 25 present the pipe size reductions and fluid inventory reductions for the advanced fluid systems as compared to high-temperature, pressurized water systems as benchmarks, under the condition of constant pumping power. Under this condition, the benefits for the phase change slurries are greater than under constant pressure drop, because of the reduced fluid flow rate. The friction-reduced systems, however, yield the same results as do the comparisons for constant pressure drop (Figs. 22 and 23), because the flow rates are not changed.

Figures 26 and 27 present similar comparisons with the low temperature, nonpressurized water system as the benchmark. Significantly greater reductions in pipe size and fluid inventory are obtained than in all the previous cases considered. Pipe sizes as small as $22 \%$ and fluid inventories as low as $5 \%$ of those for the benchmark system are projected for the system with a high Reynolds number. While these dramatic reductions may not be fully realizable in practice because of constraints not considered here, the potential advantages of the phase change and friction reduction concepts clearly warrant further investigation.

\subsection{Capacity Enhancement for Existing Systems}

As a final consideration of the benefits of friction-reducing and phase change additives, we shall examine the potential increases in heating/cooling capacity if an existing system is retrofitted to use the enhanced energy transmission fluids. The projection of increased heating/ cooling load capacity for a system that uses a phase change slurry is relatively simple, because existing preliminary information suggests that replacing water in a conventional system with a slurry will cause little reduction in flow rate (with the use of a suitable pump) while the load capacity will increase because of the heat of fusion of the phase change material and the loading ratio. On the other hand, if friction-reducing additives are used, the increase in heating/cooling capacity will be due primarily to an increase in flow rate. The latter benefit will be difficult to predict without detailed information on the characteristics of 
the specific piping layout and the pumps used. For this reason, the capacity comparisons will be based on the assumption of constant power. Implied in this assumption is that the rotation speed of the pump can be changed to maintain constant power when a friction-reducing additive is used .

The increase in heating load capacity of various combinations of friction-reducing and phase change fluids compared to the nonpressurized water system is shown in Fig. 28. The dashed lines are for the X-HDPE systems whose operating temperatures are above the boiling point of water, hence requiring pressurization. The $X-H D P E$ fluids show a heating capacity increase of 5 to 9 times over conventional water. The nonpressurized wax and $\mathrm{H}_{2} \mathrm{O}$ systems (solid lines) show a potential for 2- to 5-fold improvement over the conventional system.

The enhancement achieved by using various advanced fluids over conventional pressurized water in an existing system is shown in Fig. 29. With the X-HDPE and $\mathrm{H}_{2} \mathrm{O}$ fluids, a 2- to 5-fold enhancement in heating capacity is projected.

The enhancement of cooling capacity achieved by using an ice and water slurry rather than conventional chilled water is shown in Fig. 30 (with the $38-48^{\circ} \mathrm{F}$ system as a reference). Rather dramatic increases in capacity are possible, nearly 20-fold.

\subsection{Summary and Conclusions}

New and novel concepts are under development for improved energy transmission fluids for DHC applications. The long-range ANL program under sponsorship of the DOE with contributing efforts from other organizations is aimed at: i) establishing proof-of-concept(s) and identifying promising advanced energy transmission fluids through carefully conducted experiments, ii) conducting an assessment of technical and economic impacts of using advanced energy transmission fluids in DHC systems, and iii) generating the engineering information that will allow these new concepts to be incorporated into DHC systems.

System impact studies have shown that the use of the proposed advanced energy transmission fluids in DHC systems could result in a number of 
benefits. Some of the potential benefits reviewed in this report are summarized below. These benefits are neither independent nor additive; potential trade-offs among them must be considered in assessing the total impact of the advanced energy transmission fluid concepts.

- Heat transfer enhancement. The potential for enhancement of heat transfer by slurries acting through two different mechanisms has been suggested by laminar flow studies, by theoretical study of the phase change effect, and by the early experiments conducted at ANL. If the projections can be realized in practice, then several-fold enhancement in heat transfer may be possible, leading to either smaller heat exchange equipment or lower temperature differences.

- Flow rate reductions. The latent heat of phase change slurries leads to increased fluid heat capacity and reduced flow rate requirements. The flow rate can be as low as $18 \%$ of that of a conventional cooling system with a $\Delta \mathrm{T}$ of $\sim 10^{\circ} \mathrm{F}$, and $60 \%$ of that of a conventional heating system. The effect of reduced flow rate on pressure drop and pumping power will be discussed below.

- System pressure drop reductions. Pressure drop reductions can be the result of friction-reducing additives or flow reductions associated with phase change, or a combination of both effects. For cooling applications, a reduction in pressure drop of almost two orders of magnitude was projected. For heating applications, a reduction of one order of magnitude appears feasible.

- Pumping power reduction. The pumping power is proportional to the product of pressure drop and flow rate. Again, for cooling, a reduction of pumping power of up to two orders of magnitude appears feasible, whereas for heating applications, the projected reduction is about one order of magnitude. These are dramatic reductions indeed.

- Pipe size reductions. If, instead of reducing the pressure drop or the pumping power, we vest the improved flow characteristics and heat capacity in reduced pipe sizes, the projected reduction 
in pipe diameter can be as much as about $70 \%$ for cooling applications, or $50 \%$ for heating applications. This could result in significant reductions in the material and installation costs of the piping, as well as the cost of fluid inventories.

- Storage tank volume reductions. The use of a phase change slurry may also lead to a dramatic reduction in the size of the heat/cold storage tank required for load leveling. A reduction of up to 10-fold is projected for cooling applications with a $\Delta T$ of $\sim 10^{\circ} \mathrm{F}$, whereas a reduction of about 2.5-fold is projected in comparison with heating applications with a $\Delta \mathrm{T}$ of $\sim 30^{\circ} \mathrm{F}$.

In conclusion, the projected improvements associated with the use of the proposed advanced energy transmission fluids are dramatic. While the projection has been based on extrapolation from very limited data and much work remains to validate the practicality of the concepts, the proposed concepts are tantalizingly attractive, and further work in this area is clearly of considerable value.

\section{Acknowledgments}

This work is sponsored by the U.S. Department of Energy (DOE), Office of Buildings and Community Systems, under the District Heating and Cooling programs. The continued support of J. P. Millhone, J. Holmes and J. Kaminsky of the U.S. DOE is greatly appreciated. Thanks are also given to S. U. Choi and K. V. Liu for their contributions to this report.

\section{References}

1. Kasza, K. E., Choi, U. S., and Kaminsky, J., "Optimal Energy Transmission Fluids For District Heating and Cooling Applications," Proceedings of 77th Annual IDHCA Conference, Asheville, NC, June 1986.

2. Kasza, K. E., Choi, U. S., and Kaminsky, J., "Reducing the High Costs of District Heating and Cooling," Specifying Engineer, Vol. 56, No. 4, pp. 38-42, Oct. 1986.

3. Kasza, K. E. and Chen, M. M., "Development of Enhanced Heat Transfer/ Transport/Storage Slurries for Thermal System Improvement," Argonne National Laboratory, ANL-82-50, June 1982. 
4. Kasza, K. E. and Chen, M. M., "Improvement of the Performance of Solar Energy or Waste Heat Utilization Systems by Using Phase-Change Slurry as an Enhanced Heat-Transfer Storage Fluid," ASME Journal of Solar Engineering, Vol. 107, pp. 229-236, August 1985.

5. Soo, S. L., Dynamics of Multiphase Fluids, Blaisdell, 1960.

6. Sohn, C. W., and Chen, M. M., "Microconvective Thermal Conductivity in Disperse Two-Phase Mixtures as Observed in a Low Velocity Couette Flow Experiment," Journal of Heat Transfer, Vol. 103, pp. 47-51, 1981.

7. Sohn, C. W., and Chen, M. M., "Heat Transfer Enhancement in Laminar Slurry Pipe Flow With Power Law Thermal Conductivities," Journal of Heat Transfer, Vol. 106, pp. 539-542, 1984.

8. Chen, K. and Chen, M. M., "An Analytical and Experimental Investigation of the Convective Heat Transfer of Phase-Transition Slurry Flow," to be presented at and published in the Proceedings of International Symposium on Multiphase Flows, August 3-5, 1987, Hangzhow, People's Republic of China.

9. Kasza, K. E., Choi, S. U., and Kaminsky, J., "Advanced Energy Transmission Fluids For Heating and Cooling Systems," ASHRAE Transactions, Vol. 93, Pt. 2, 1987. 
Table 1. Theoretical Enhancement Ratios for Thermal Conductivity and Heat Transfer Coefficients in Slurry Flow in Pipes Without Phase Change

\begin{tabular}{|c|c|c|c|c|c|}
\hline \multirow[b]{2}{*}{ Velocity, $\mathrm{m} / \mathrm{s}$} & \multirow[b]{2}{*}{$\begin{array}{c}\text { Particle } \\
\text { Diameter, } \mathrm{mm}\end{array}$} & \multicolumn{2}{|c|}{$\begin{array}{c}\text { Laminar Flow } \\
\text { Fully } \\
\text { Developed }^{\mathrm{a}} \\
\end{array}$} & \multicolumn{2}{|c|}{$\begin{array}{c}\text { Turbulent Flow } \\
\text { Fully } \\
\text { Developed }\end{array}$} \\
\hline & & $\begin{array}{c}\text { 3-mm-dia } \\
\text { tube } \\
\end{array}$ & $\begin{array}{c}10-\mathrm{mm}-\mathrm{dia} \\
\text { tube }\end{array}$ & $\begin{array}{c}3-\mathrm{mm}-\mathrm{dia} \\
\text { tube } \\
\end{array}$ & $\begin{array}{l}10-\mathrm{mm}-\mathrm{dia} \\
\text { tube } \\
\end{array}$ \\
\hline \multirow[t]{3}{*}{0.1} & 0.1 & -- & -- & -- & -- \\
\hline & 0.3 & $<2$ & -- & $<1.6$ & -- \\
\hline & 1 & 5.5 & 3.0 & 3.1 & 2.1 \\
\hline \multirow[t]{3}{*}{1} & 0.1 & $<2$ & -- & $<1.6$ & -- \\
\hline & 0.3 & 5.2 & 2.8 & 3.0 & 2.0 \\
\hline & 1 & 17 & 9.5 & 6.7 & 4.5 \\
\hline \multirow[t]{3}{*}{10} & 0.1 & 5.5 & 3.0 & 3.1 & 2.1 \\
\hline & 0.3 & 16 & 9 & 6.5 & 4.3 \\
\hline & 1 & 55 & 30 & 14 & 10 \\
\hline
\end{tabular}

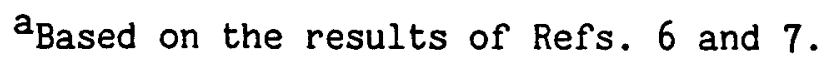

based on the assumption that the particle diameters are small relative to the laminar sublayer and that the slurry behaves as a single-phase fluid of similar bulk properties. See Eq. (3) of Ref. 3. 
Table 2. Heat Capacity and Related Benefits for District Heating

\begin{tabular}{lll} 
Relative Heat & Relative & Relative \\
Capacity Per Pound & Storage Heat & Storage Tank \\
of Working Fluid & Tank Volume Heat Loss \\
\hline
\end{tabular}

Nonpressurized Systems

$\begin{array}{lccc}\begin{array}{l}\text { Water, } 180^{\circ} \mathrm{F} / 150^{\circ} \mathrm{F} \\ \text { (Reference System) }\end{array} & 1.00 & 1.00 & 1.00 \\ \begin{array}{l}\text { Stearic Acid + Water, } \\ 180^{\circ} \mathrm{F} / 150^{\circ} \mathrm{F}^{*}\end{array} & 1.74 & 0.40 & 0.54\end{array}$

Pressurized Systems

$\begin{array}{llll}\text { Water, } 248^{\circ} \mathrm{F} / 140^{\circ} \mathrm{F} & 3.60 & 0.28 & 0.61 \\ \begin{array}{c}\mathrm{X} \text {-HDPE + Water, } \\ 275^{\circ} \mathrm{F} / 140^{\circ} \mathrm{F} *\end{array} & 4.61 & 0.21 & 0.56\end{array}$

*Assumed mass fraction of phase change material is $30 \%$ for circulating media, $60 \%$ for storage media. 


\section{SLURRY HEAT TRANSFER TEST FACILITY}

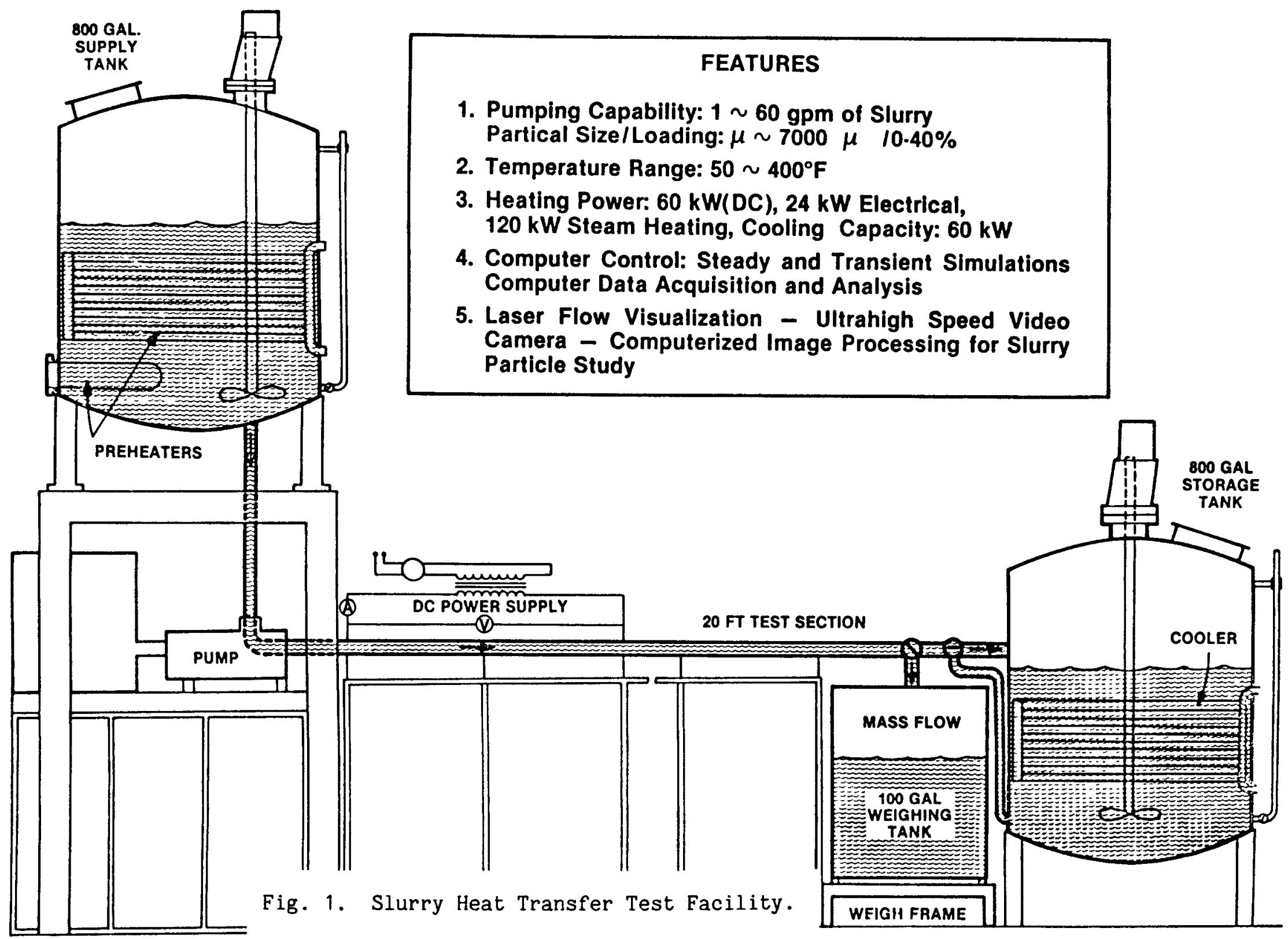




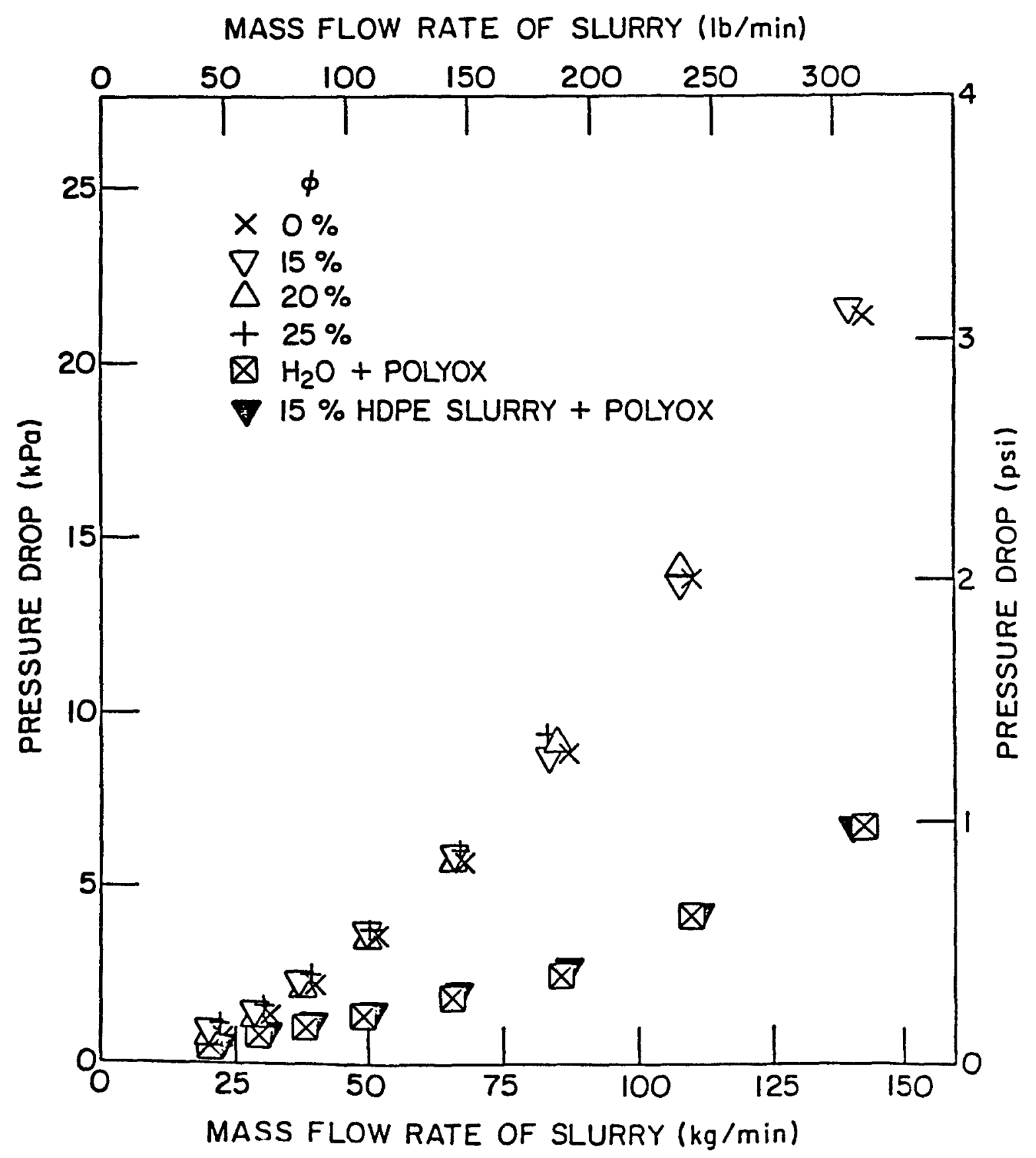

Fig. 2a. Influence of Solids Volume Loading and Friction-Reducing Additives on Pressure Drop Associated with Flow of X-HDPE in a Pipe. 


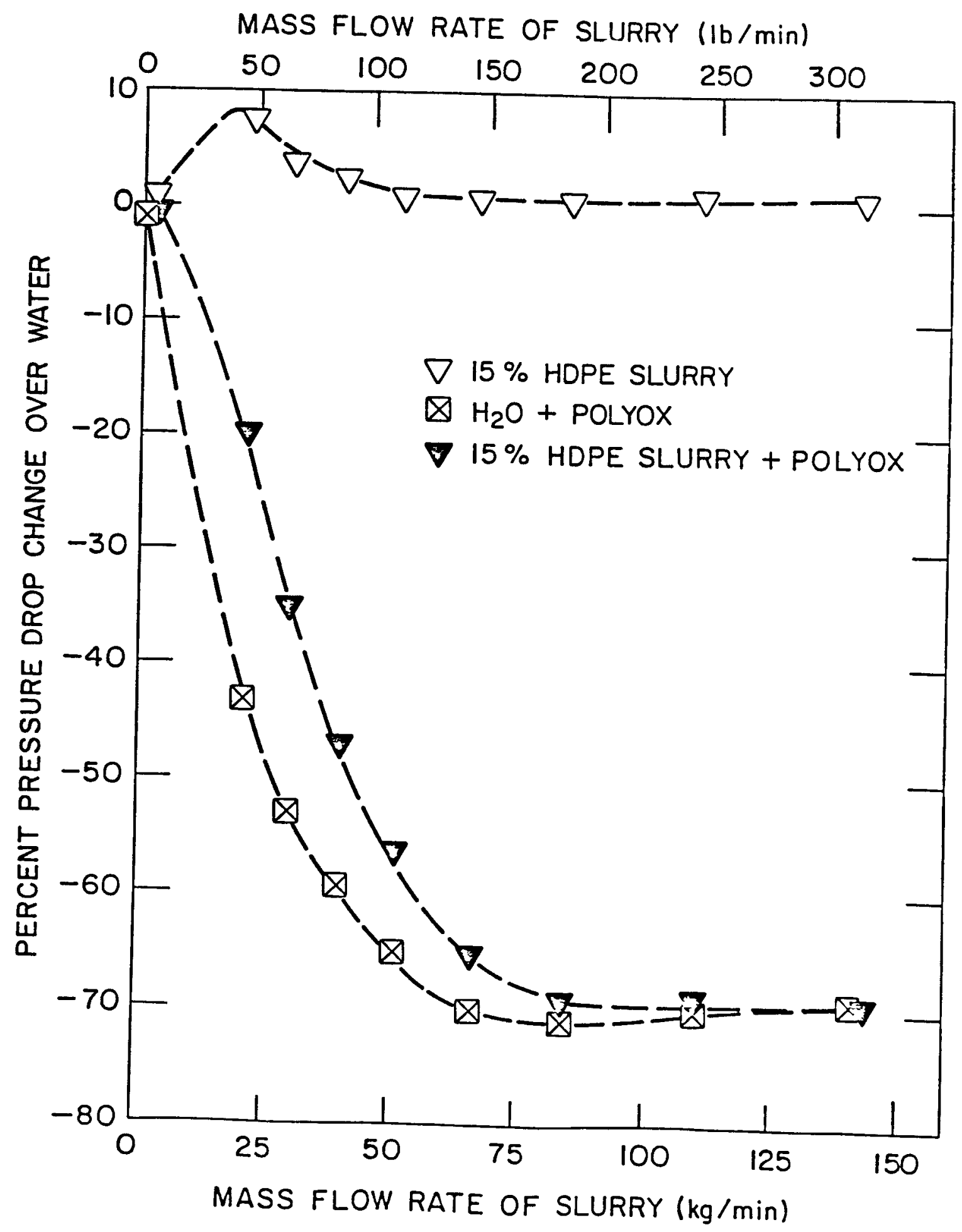

Fig. 2b. Percent Pressure Drop Change Over Water vs. Mass Flow Rate of
Slurry. 


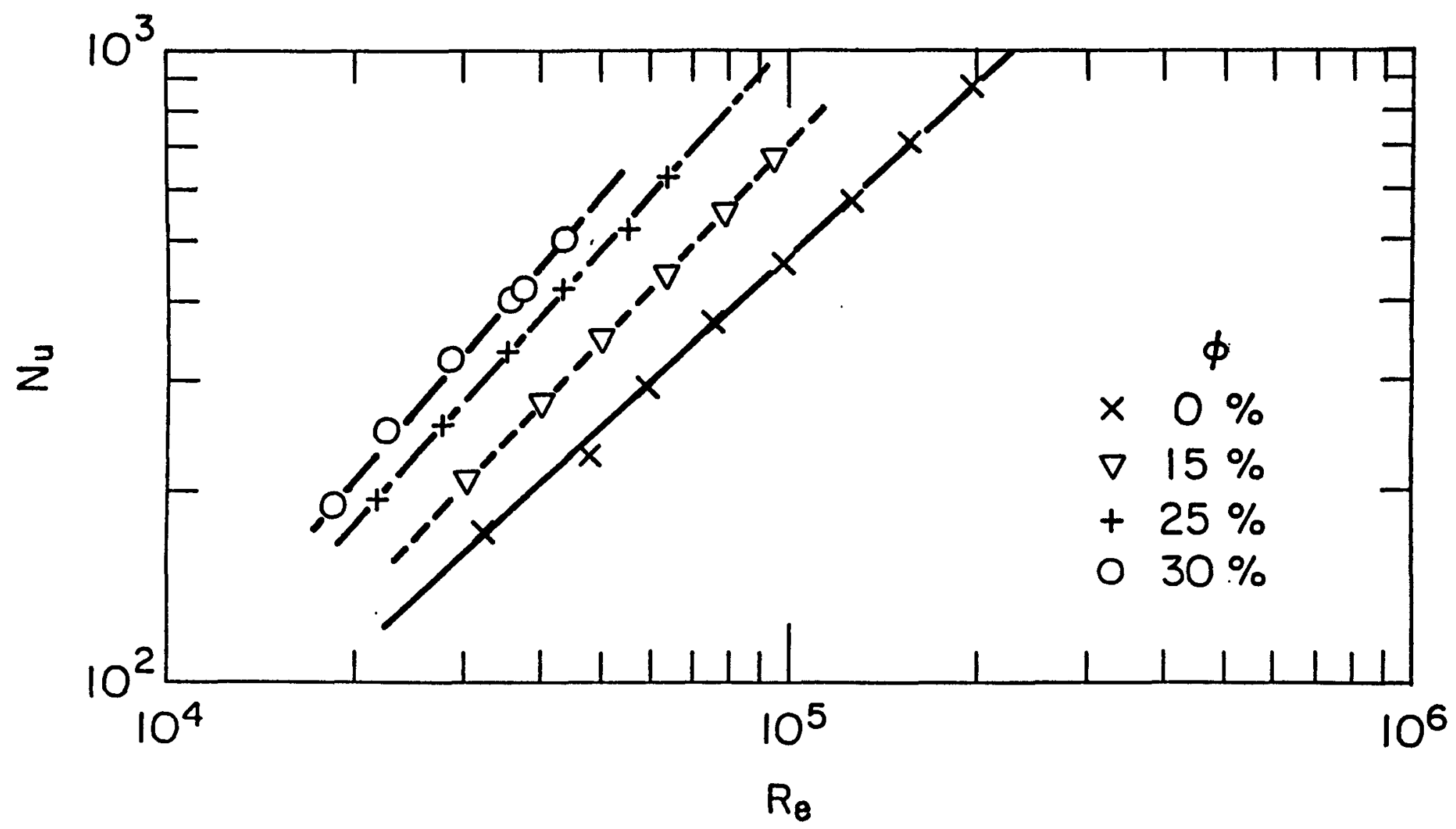

Fig. 3. Variation of Heat Transfer Nusselt Number (Nu) For Slurry of $X-H D P E$ and Pure Water Versus Effective Pipe Reynolds Number (Re) for Various Slurry Loadings ( $\phi)$. 


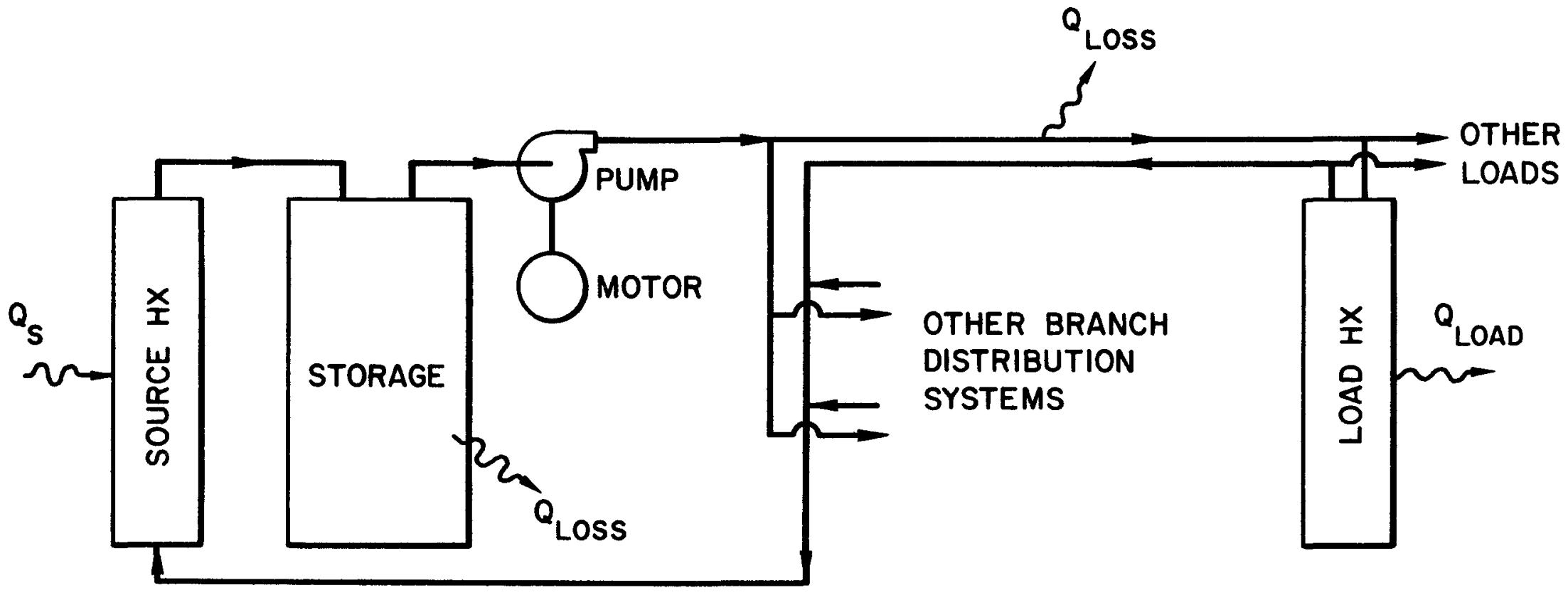

Fig. 4. Assumed System for Comparison of Enhanced Energy Transmission Fluids with Conventional Fluids in DHC Applications. 


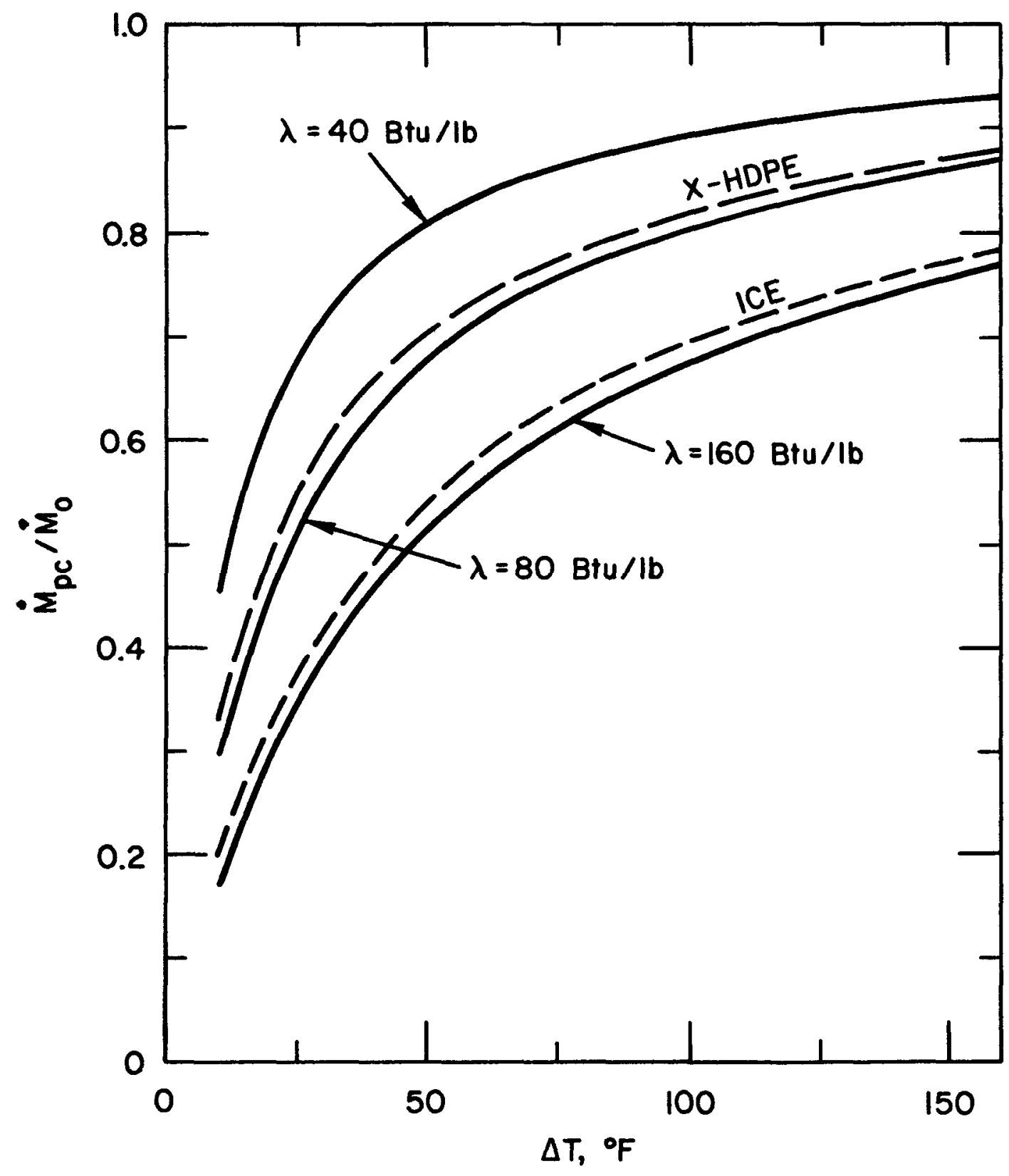

Fig. 5. Ratio of Mass Flow between Phase Change Slurry $\left(\hat{M}_{p c}\right)$ and
Conventional Single-Phase Sensible-Heat Fluid ( $\left.\mathbb{M}_{0}\right)$ for $\phi=30 \%$. 


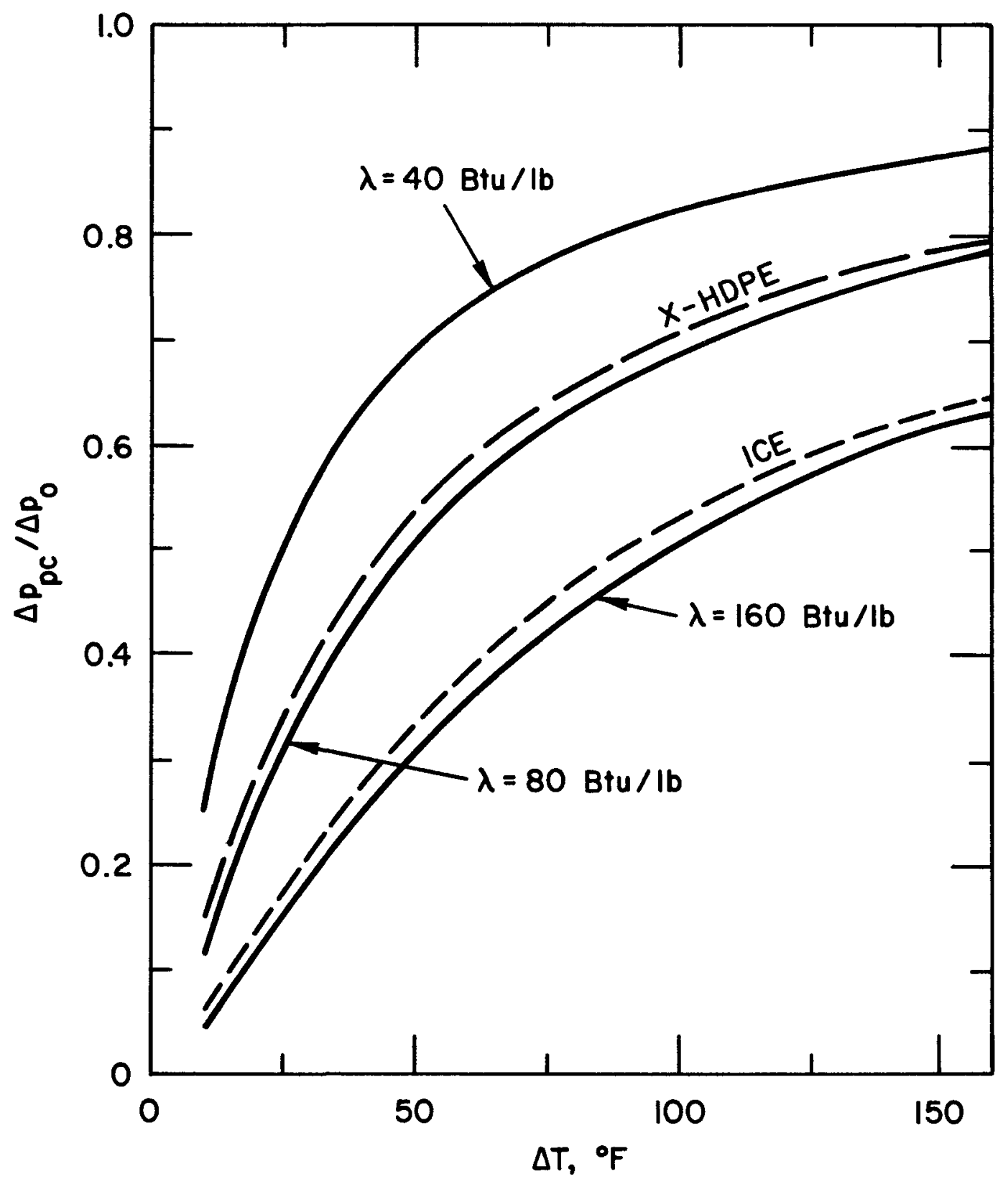

Fig. 6. Ratio of Pressure Drop between Phase Change Slurry $\left(\Delta \mathrm{p}_{\mathrm{pc}}\right)$ and Conventional Sensible-Heat System $\left(\Delta p_{0}\right)$ for $\phi=30 \%$. 


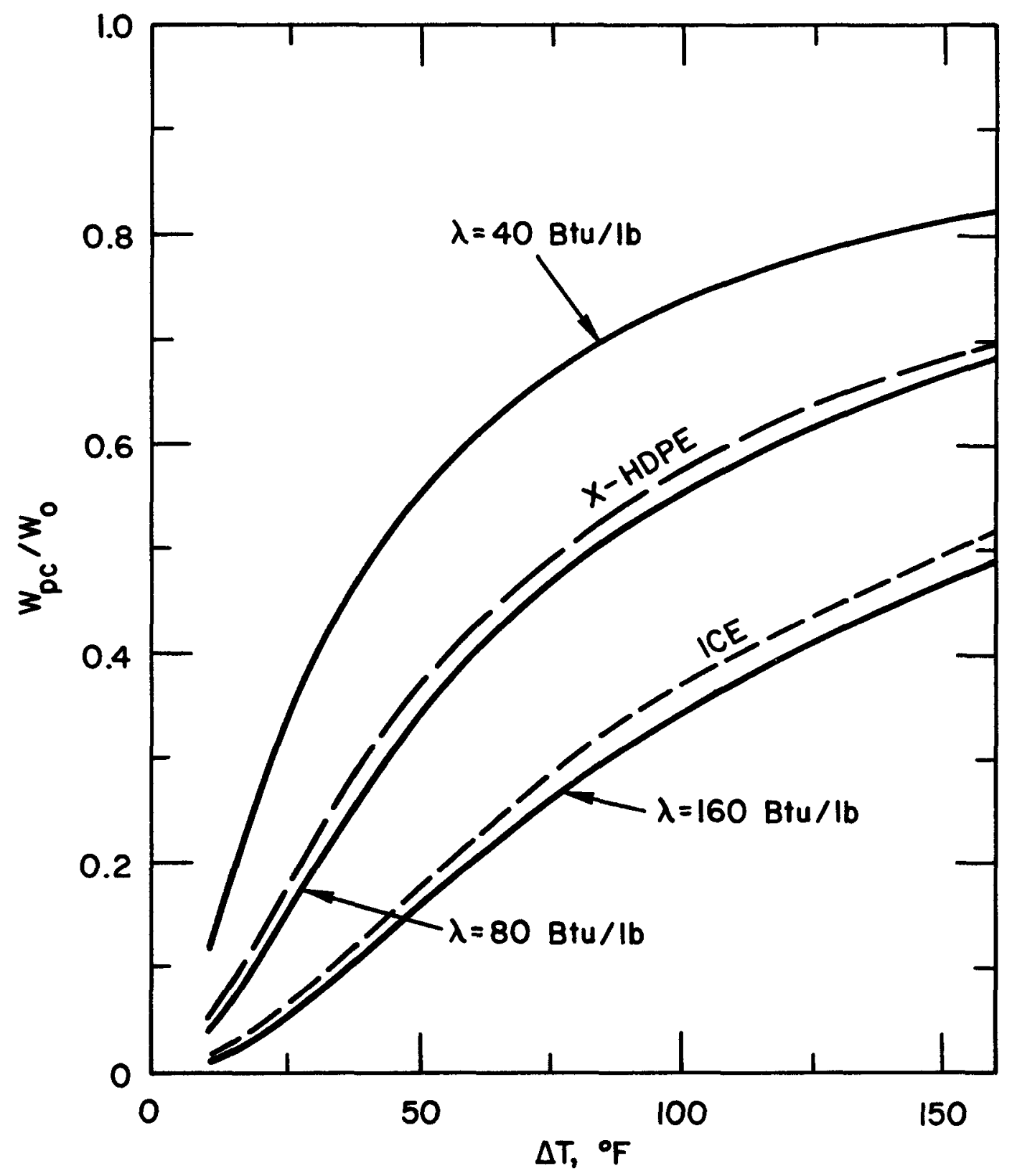

Fig. 7. Ratio of Pumping Power between Phase Change Slurry $\left(W_{p c}\right)$ and Conventional Sensible-Heat System $\left(W_{0}\right)$ for $\phi=30 \%$. 


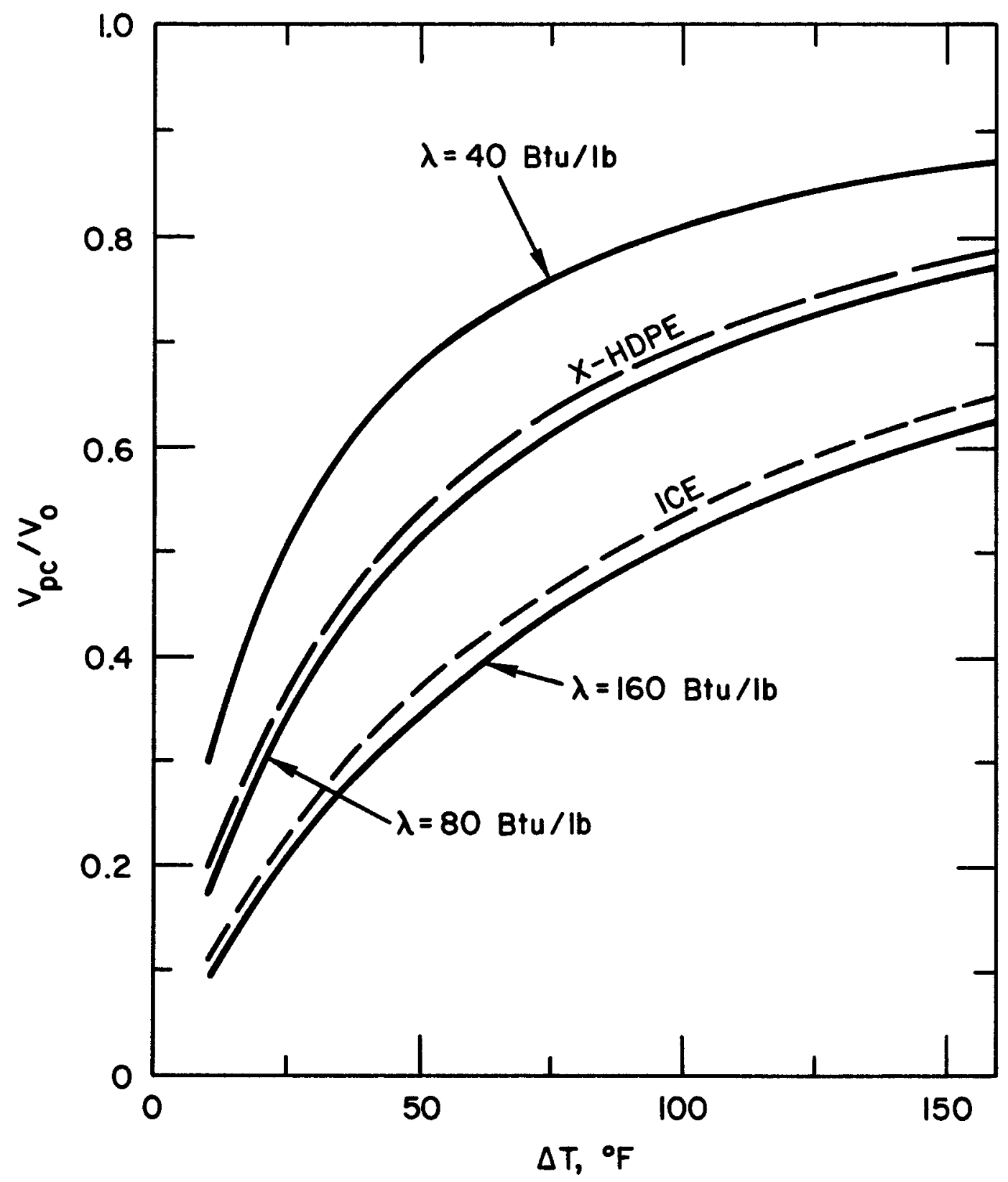

Fig. 8. Ratio of Storage Volume between Phase Change Slurry $\left(V_{p c}\right)$ and a Conventional Single-Phase System $\left(V_{0}\right)$ for $\phi=60 \%$. 


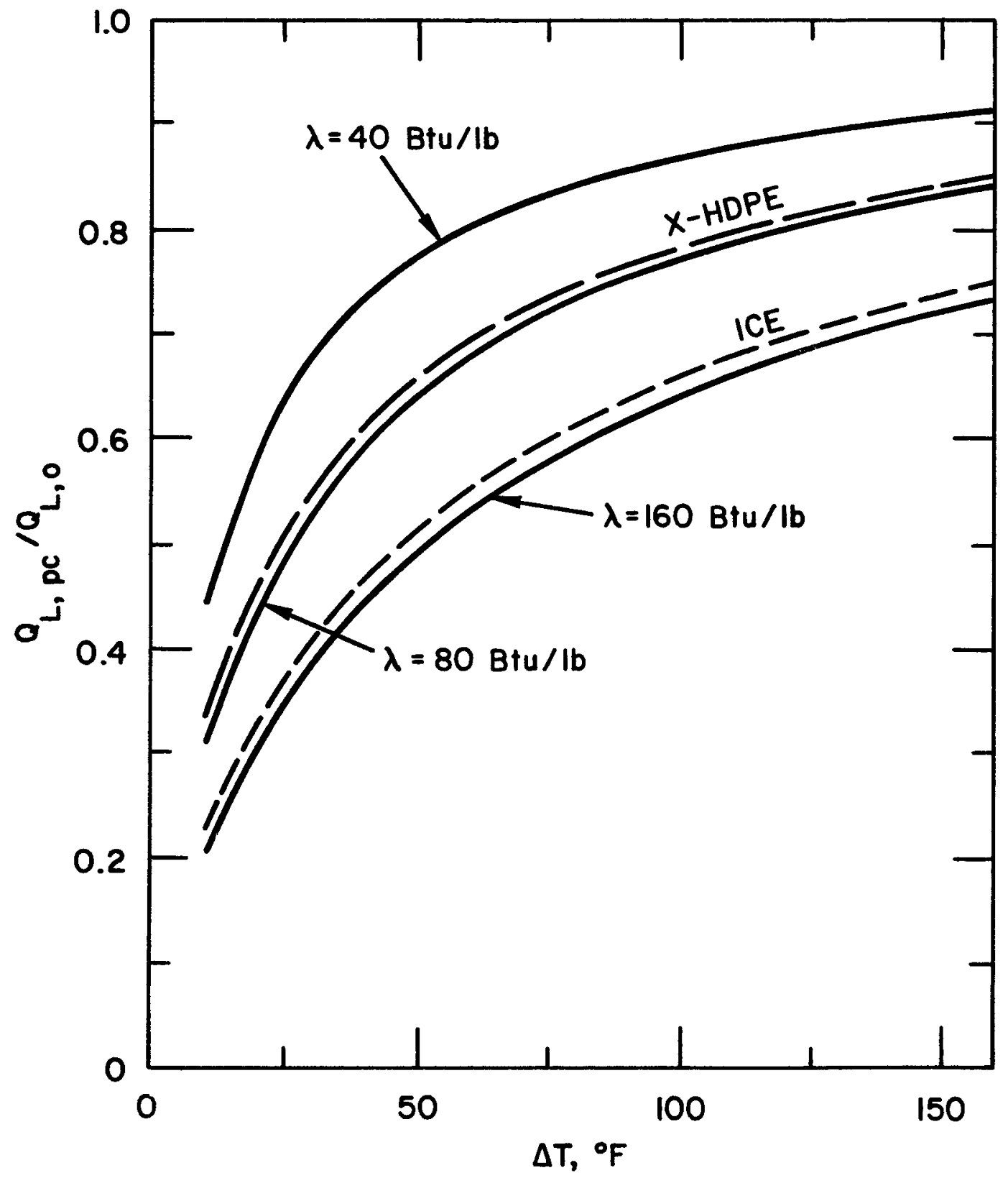

Fig. 9. Ratio of Slurry Storage Tank Heat Loss for a Phase Change Slurry System $\left(Q_{L, p c}\right)$ and a Conventional System $\left(Q_{L, o}\right)$ for Various Source-to-Sink Total Temperature Differences, $\Delta T$. 


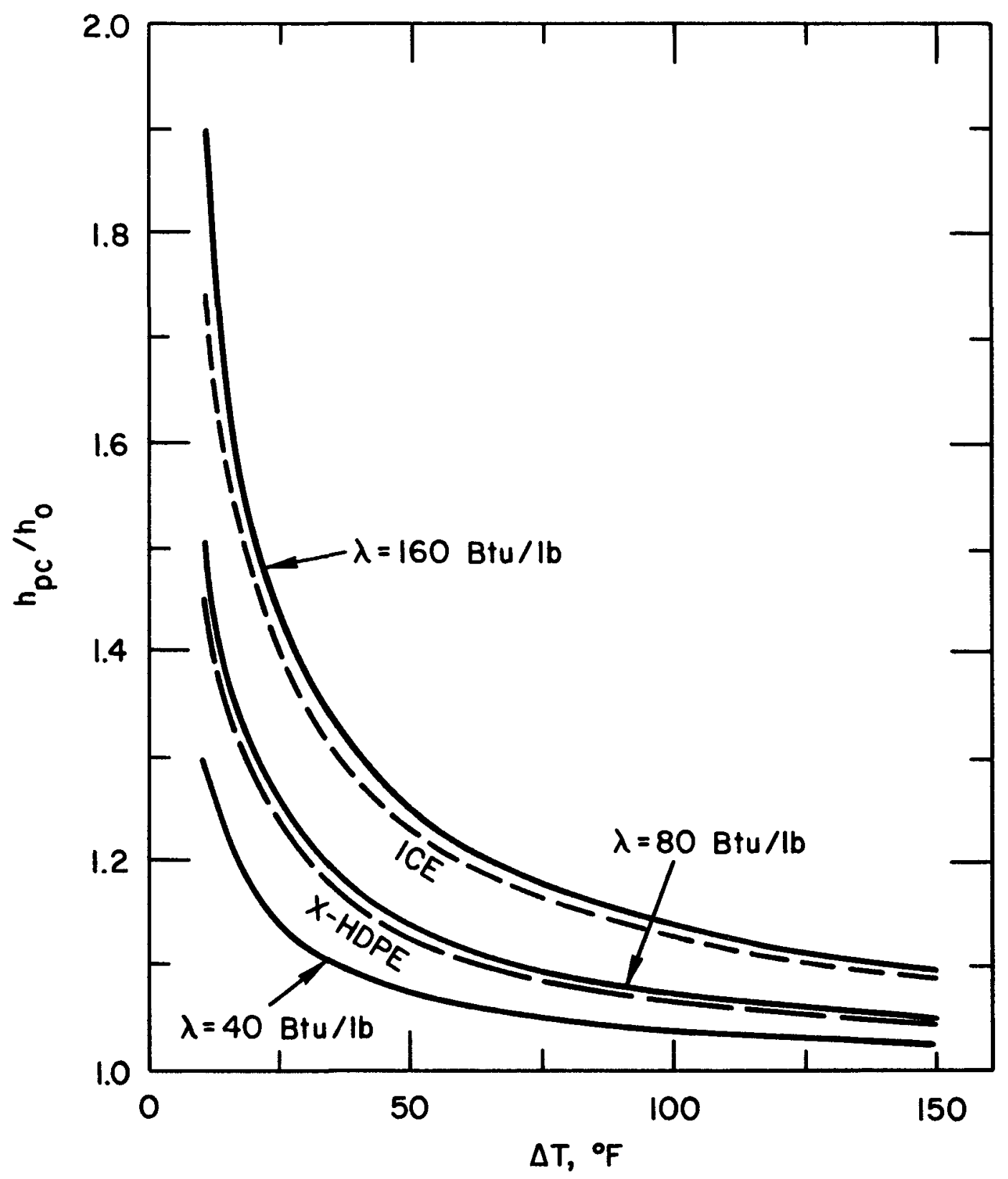

Fig. 10. Potential Heat Transfer Enhancement Due to the Use of Phase Change Slurry. 


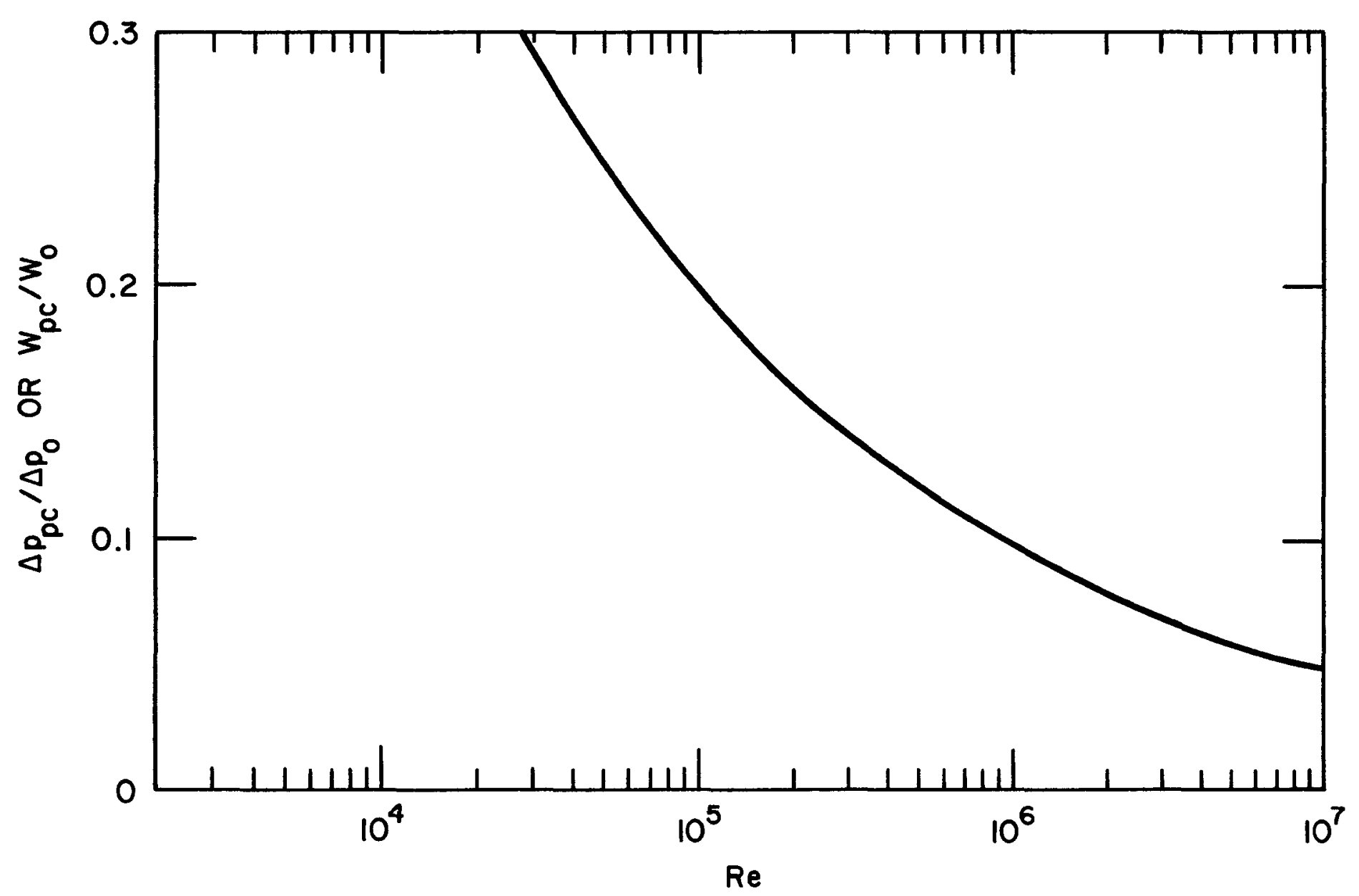

Fig. 11. Pressure Drop Reduction and Pumping Power Reduction Due to a Friction-Reducing Additive as a Function of the Reynolds Number for a Pipe of Constant Diameter. 
0.18

0.10

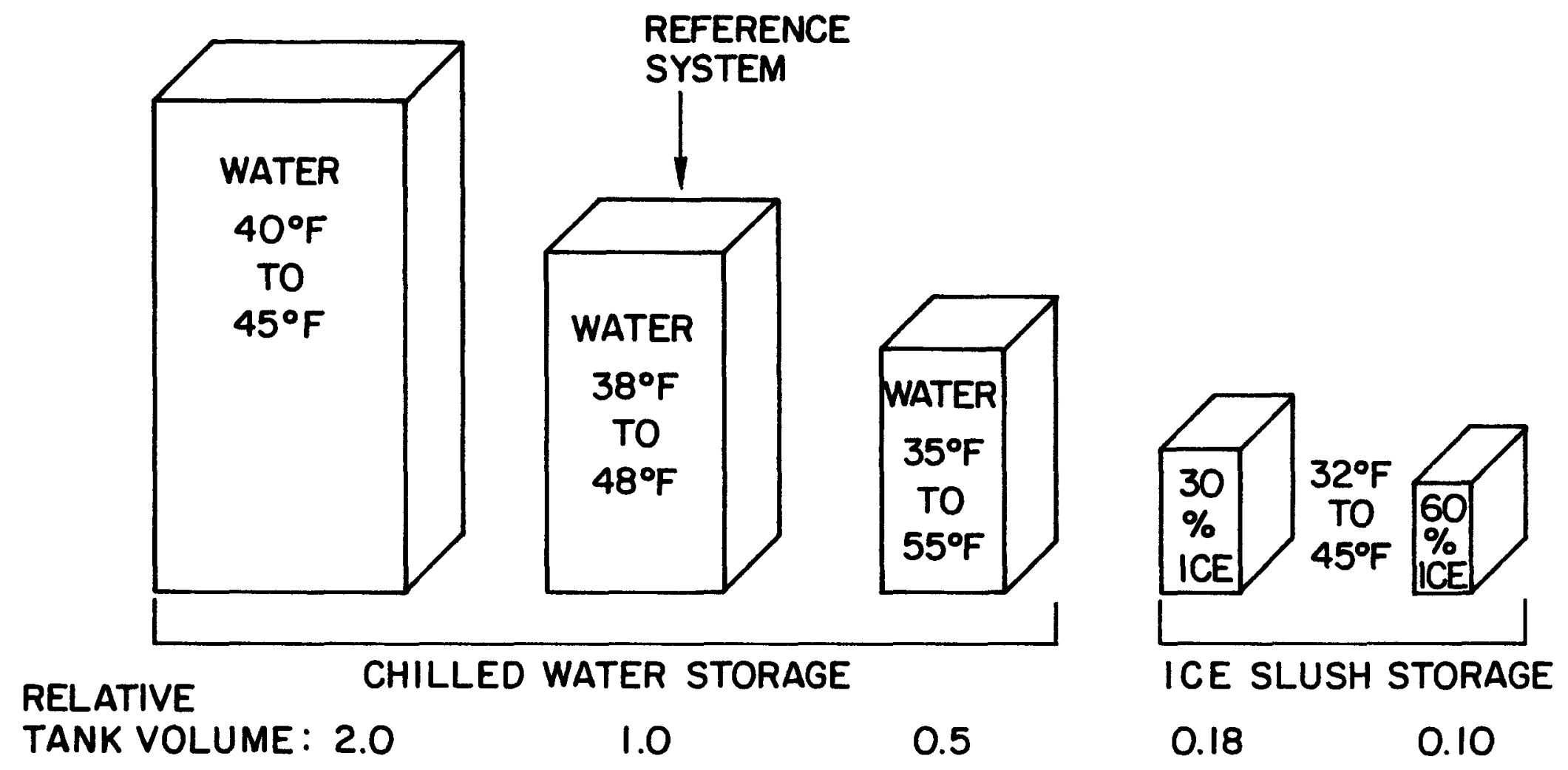

Fig. 12. Comparison of Coolant Flow Rate and Cold Storage Tank Volume for Ice Slush Slurry and Conventional Chilled Water for District Cooling Applications. 


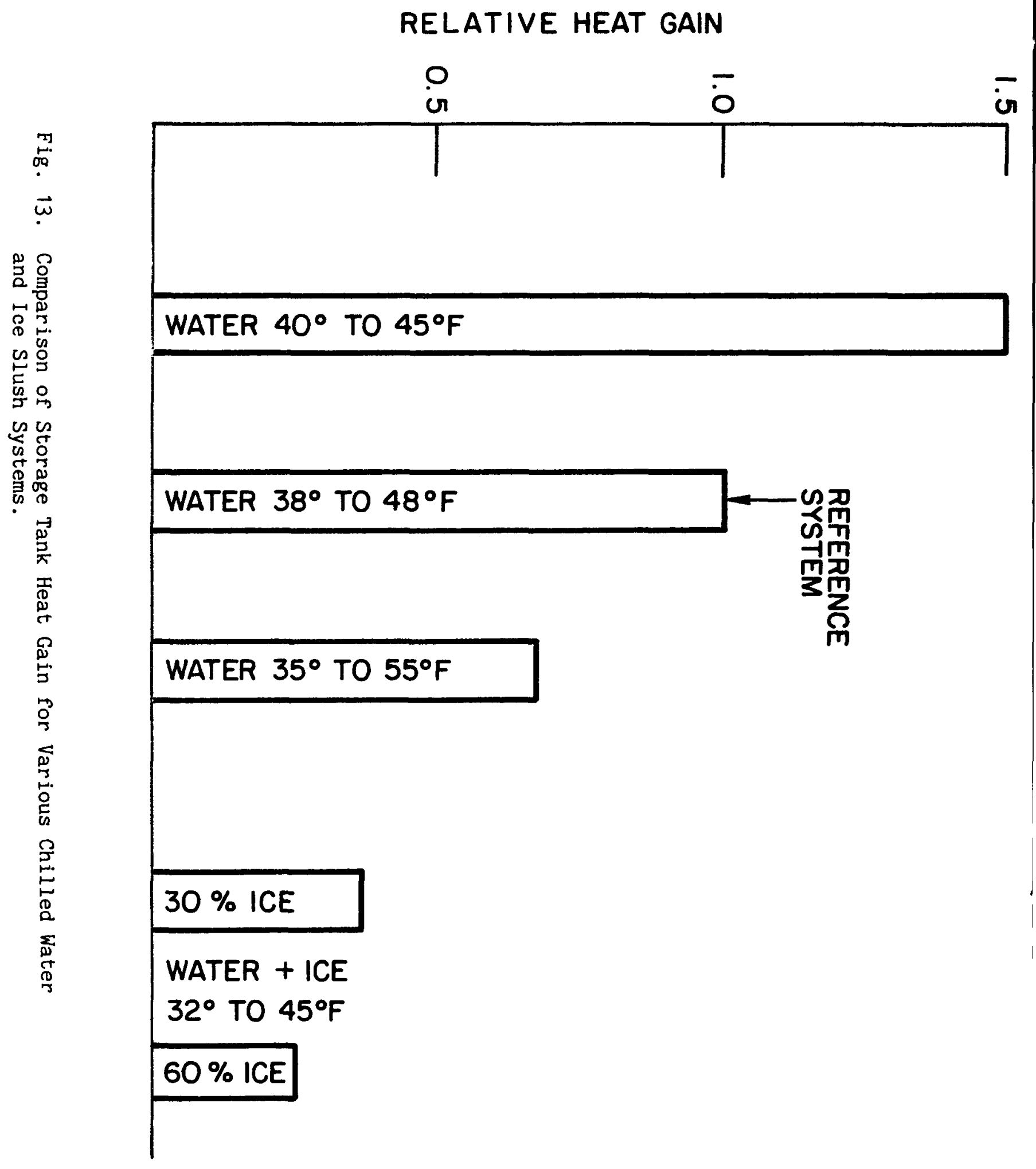




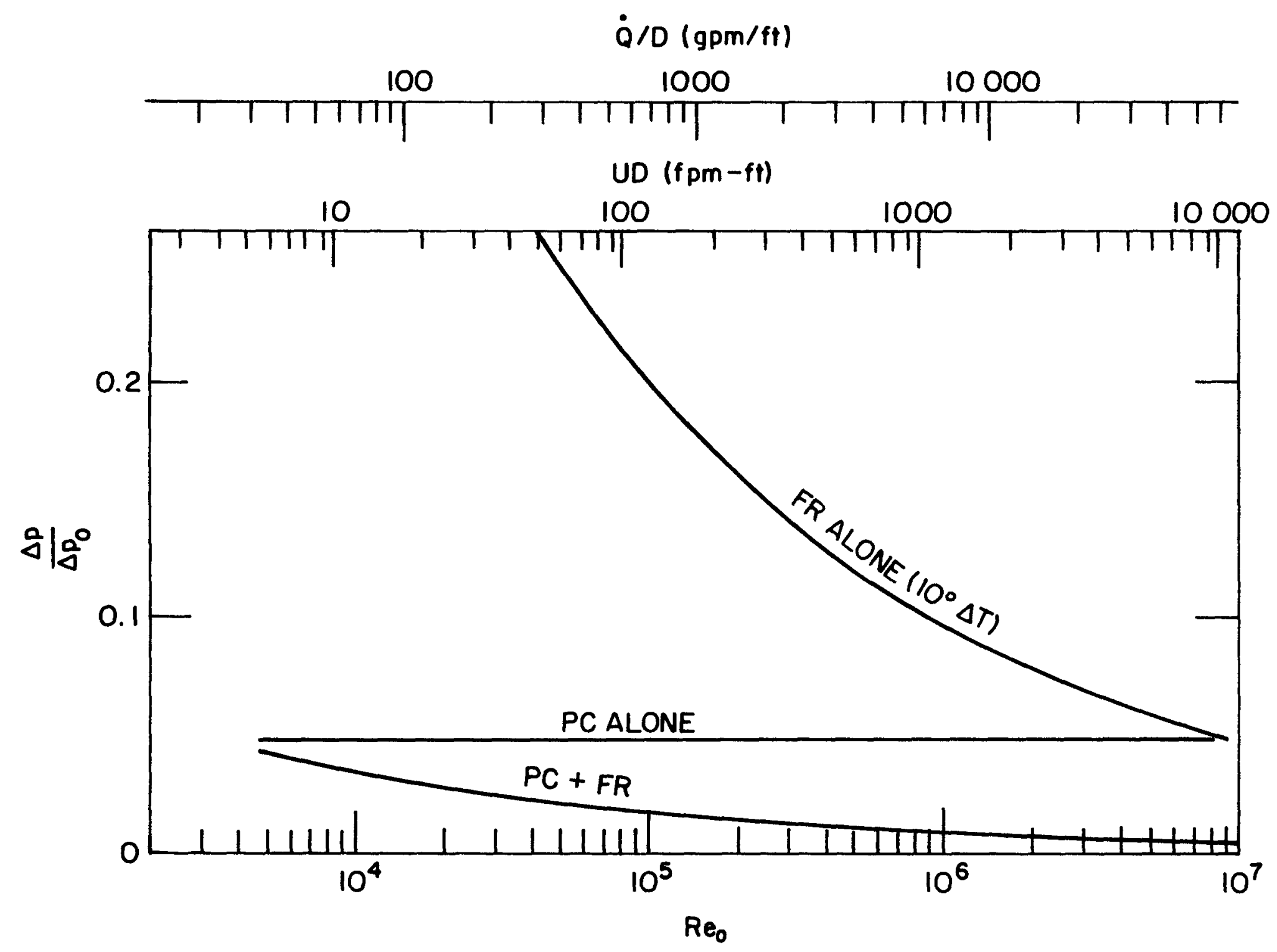

Fig. 14. Comparison of Pressure Drop for Advanced Energy Transmission Fluids with That for Conventional Fluids at Constant Pipe Diameter. 


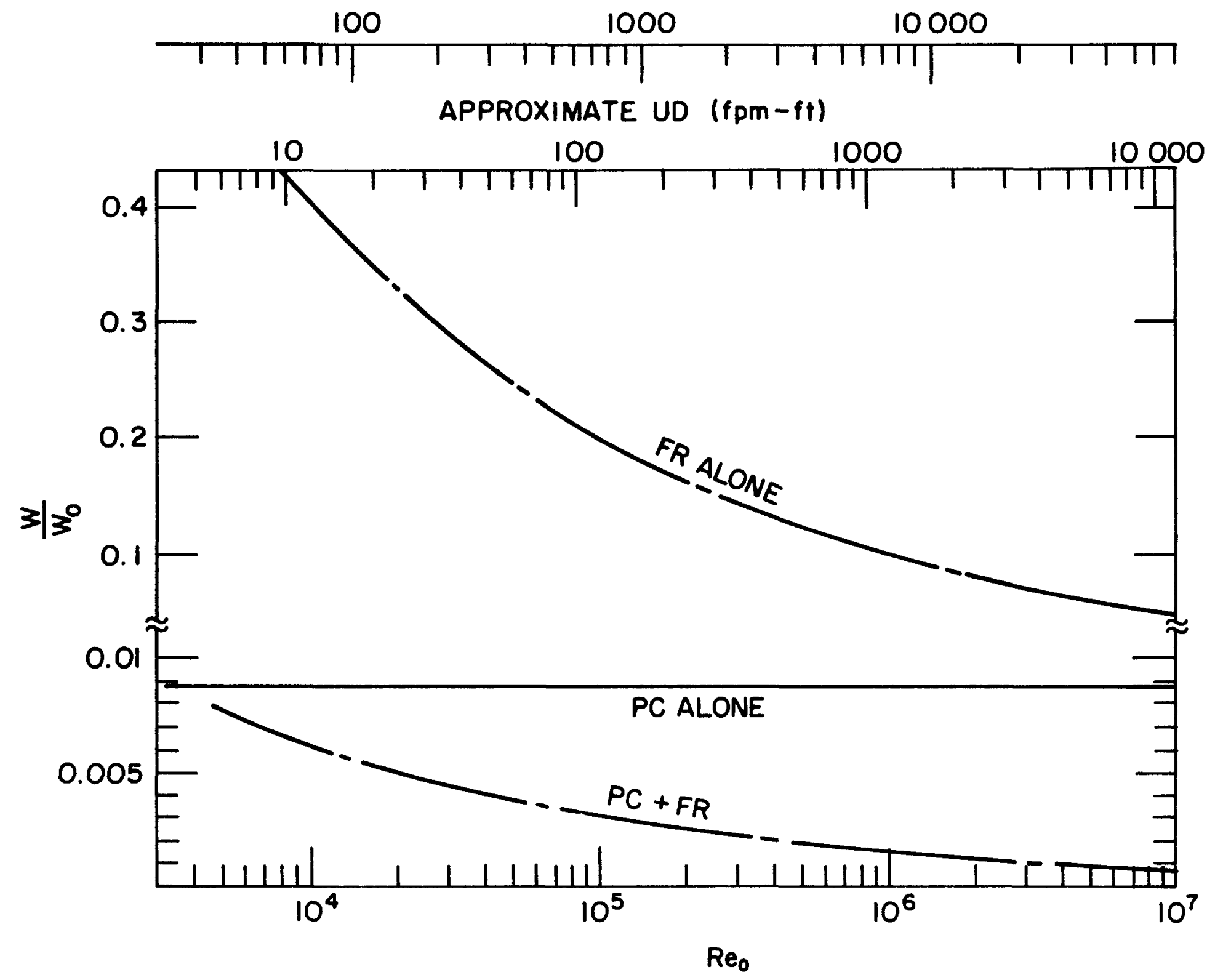

Fig. 15. Comparison of Pumping Power for Advanced Energy Transmission Fluids with That for Conventional Fluids at Constant Pipe Diameter. 


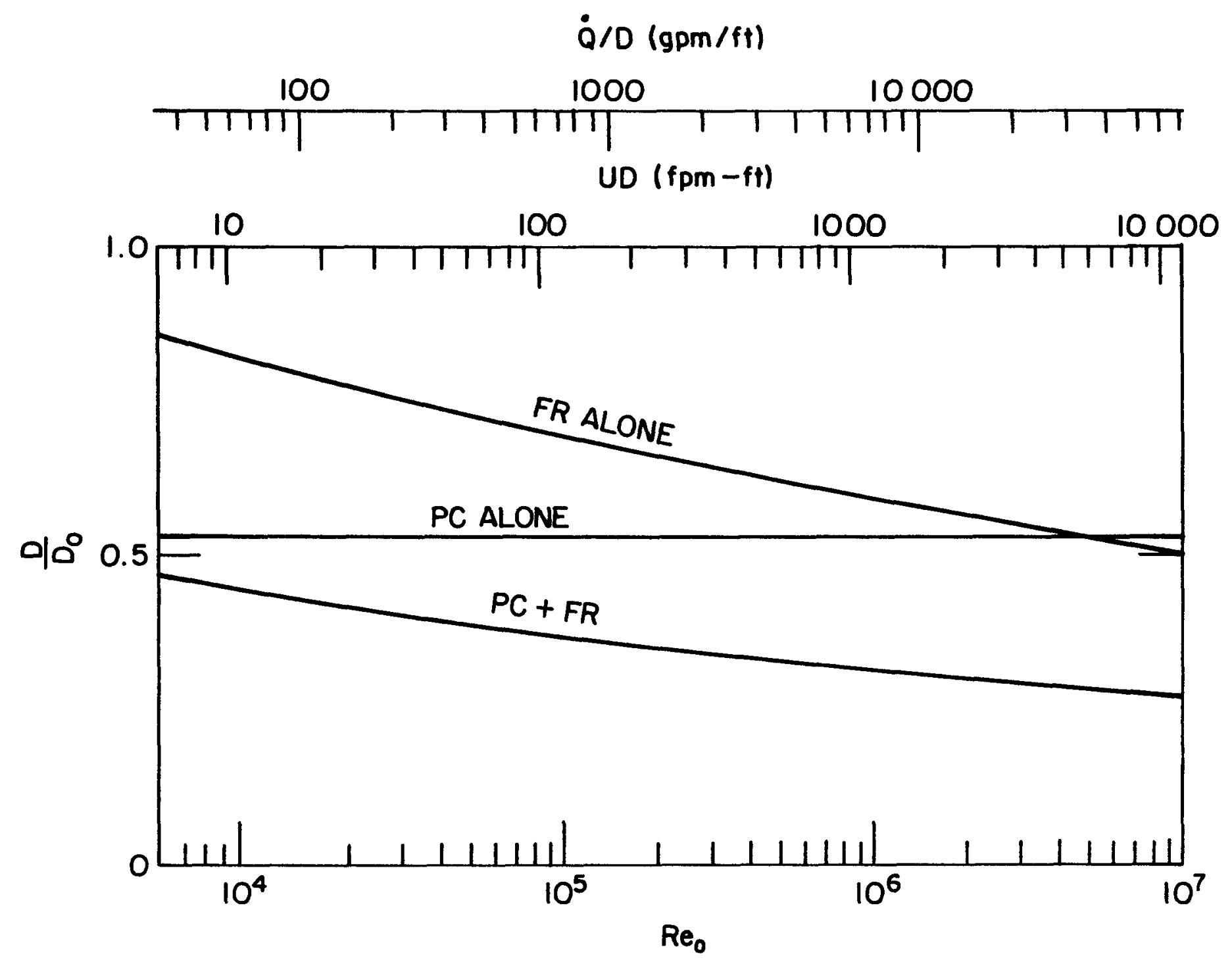

Fig. 16. Reduction of Pipe Diameter for Advanced Energy Transmission Fluids Compared to That of Conventional Fluids at Constant Pressure Drop. 


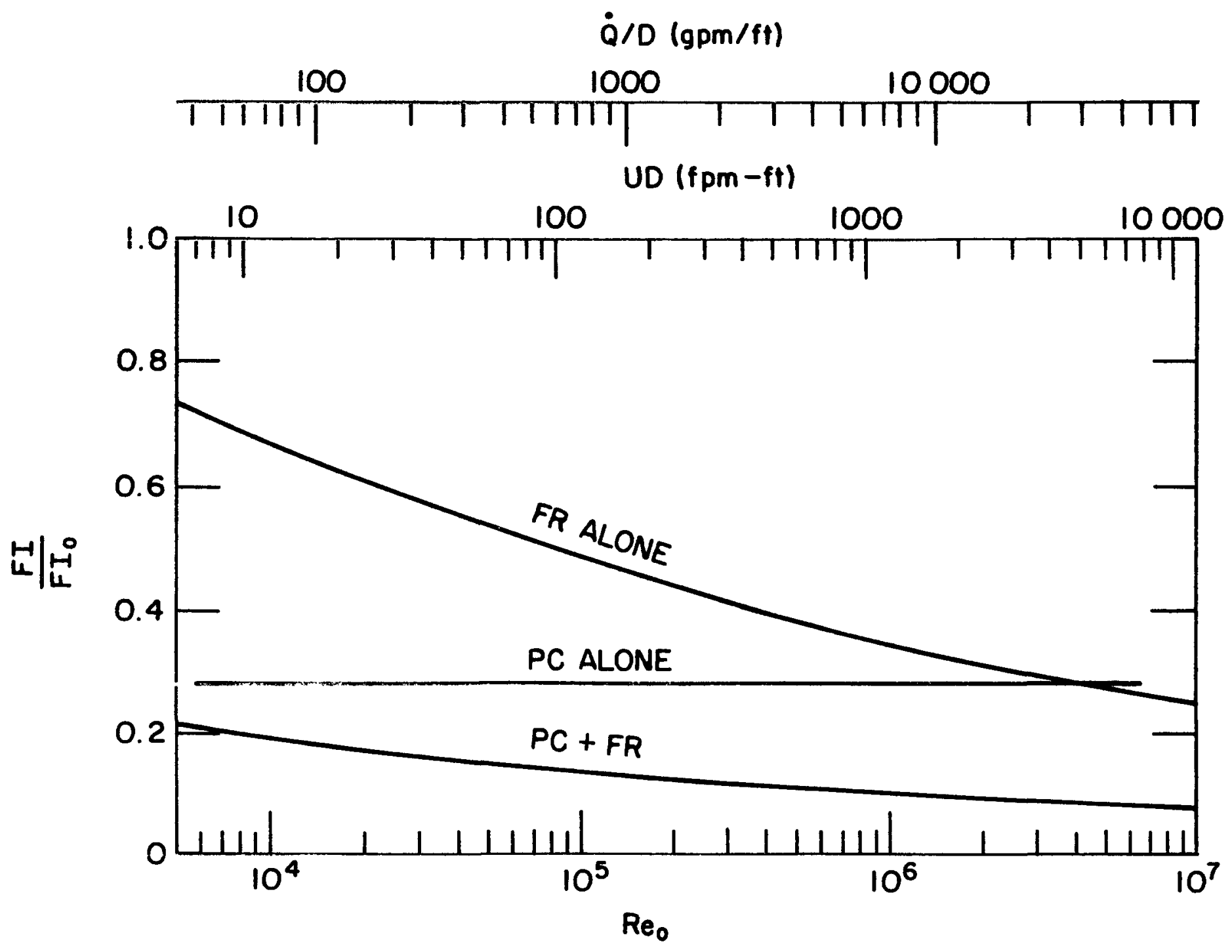

Fig. 17. Reduction of Fluid Inventory of Advanced Energy Transmission

Fluids Compared to Conventional Fluids at Constant Pressure Drop. 


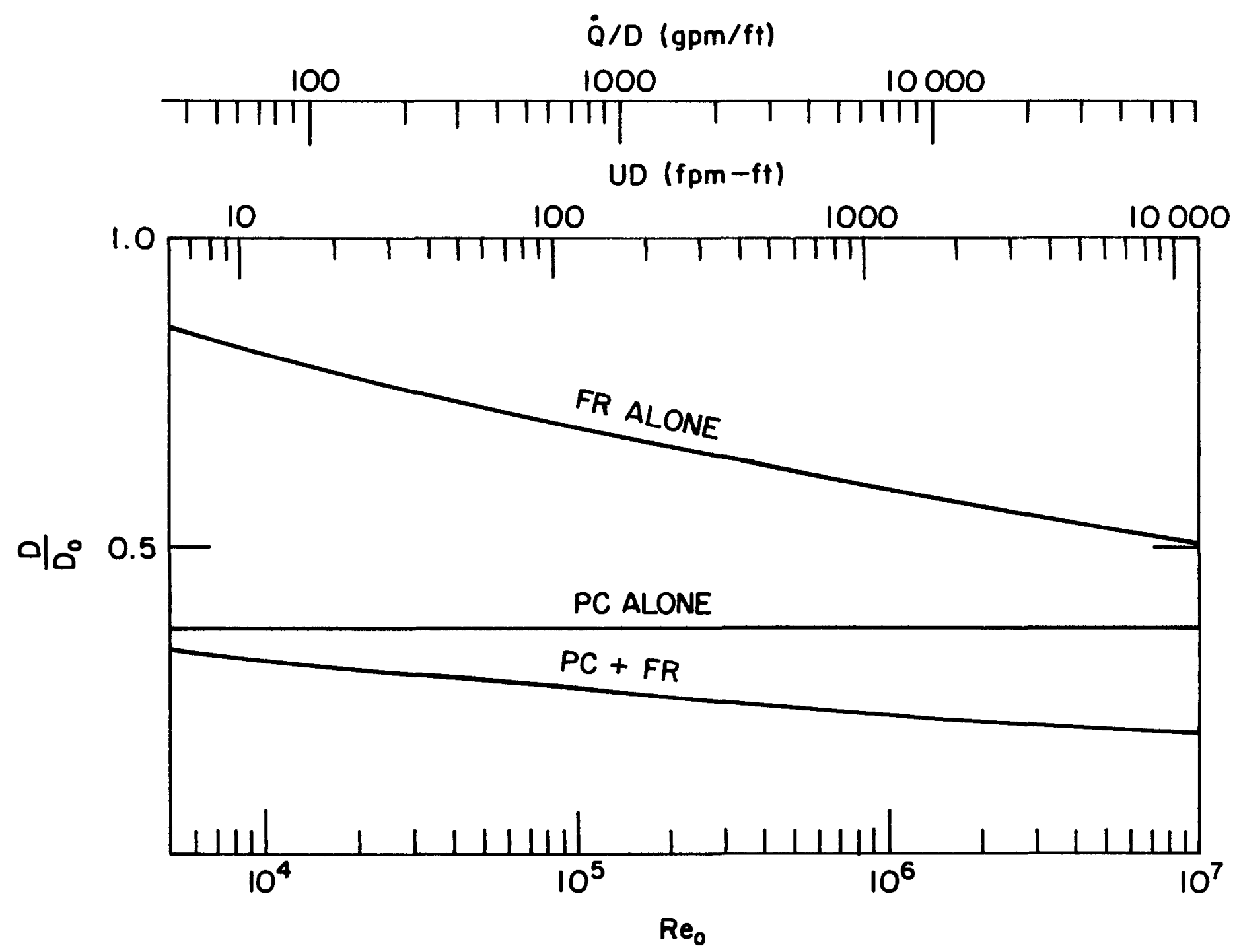

Fig. 18. Pipe Size Reductions of Advanced Energy Transmission Fluids Compared to Conventional Fluids at Constant Power. 


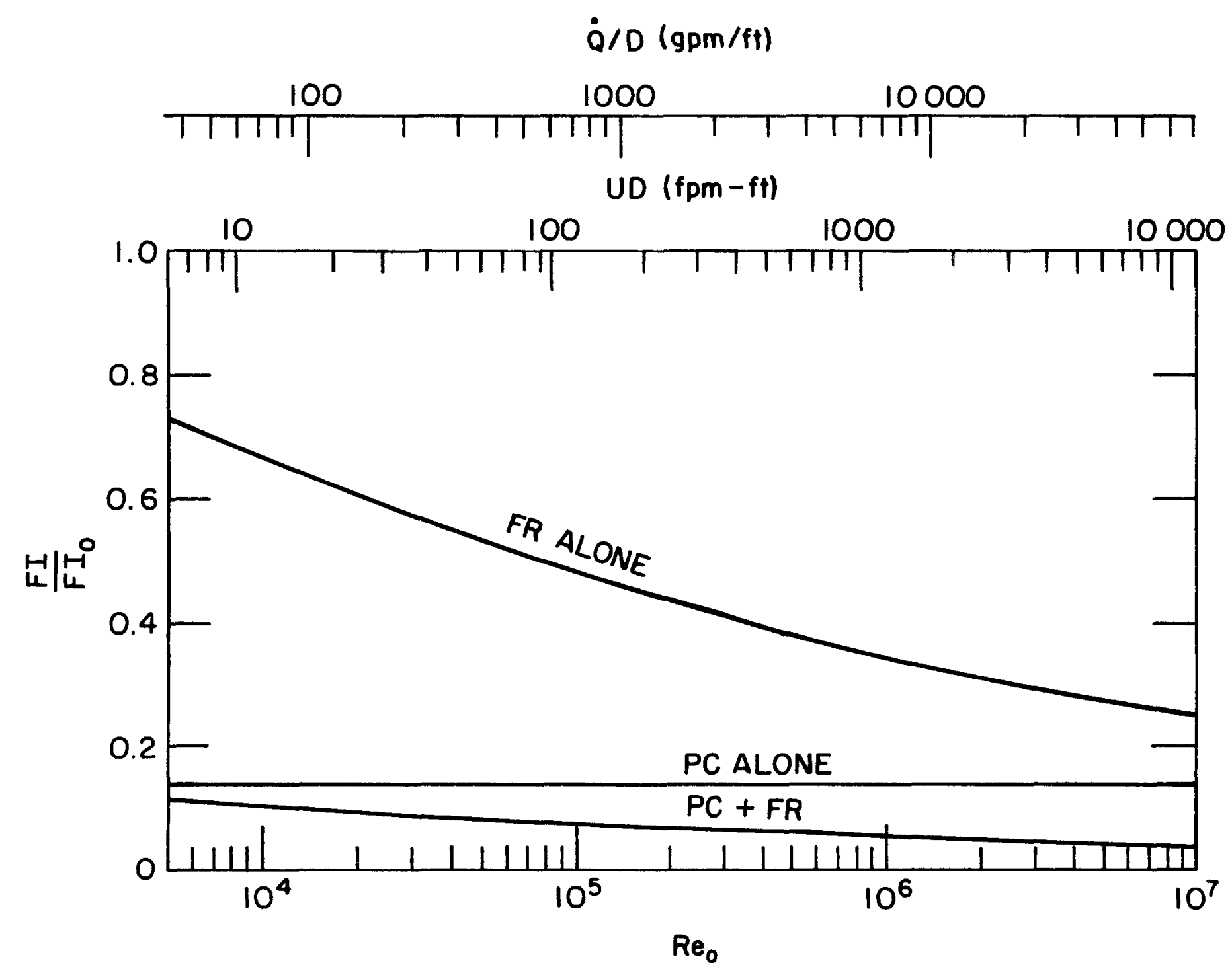

Fig. 19. Fluid Inventory Reductions of Advanced Energy Transmission Fluids Compared to Conventional Fluids at Constant Power. 


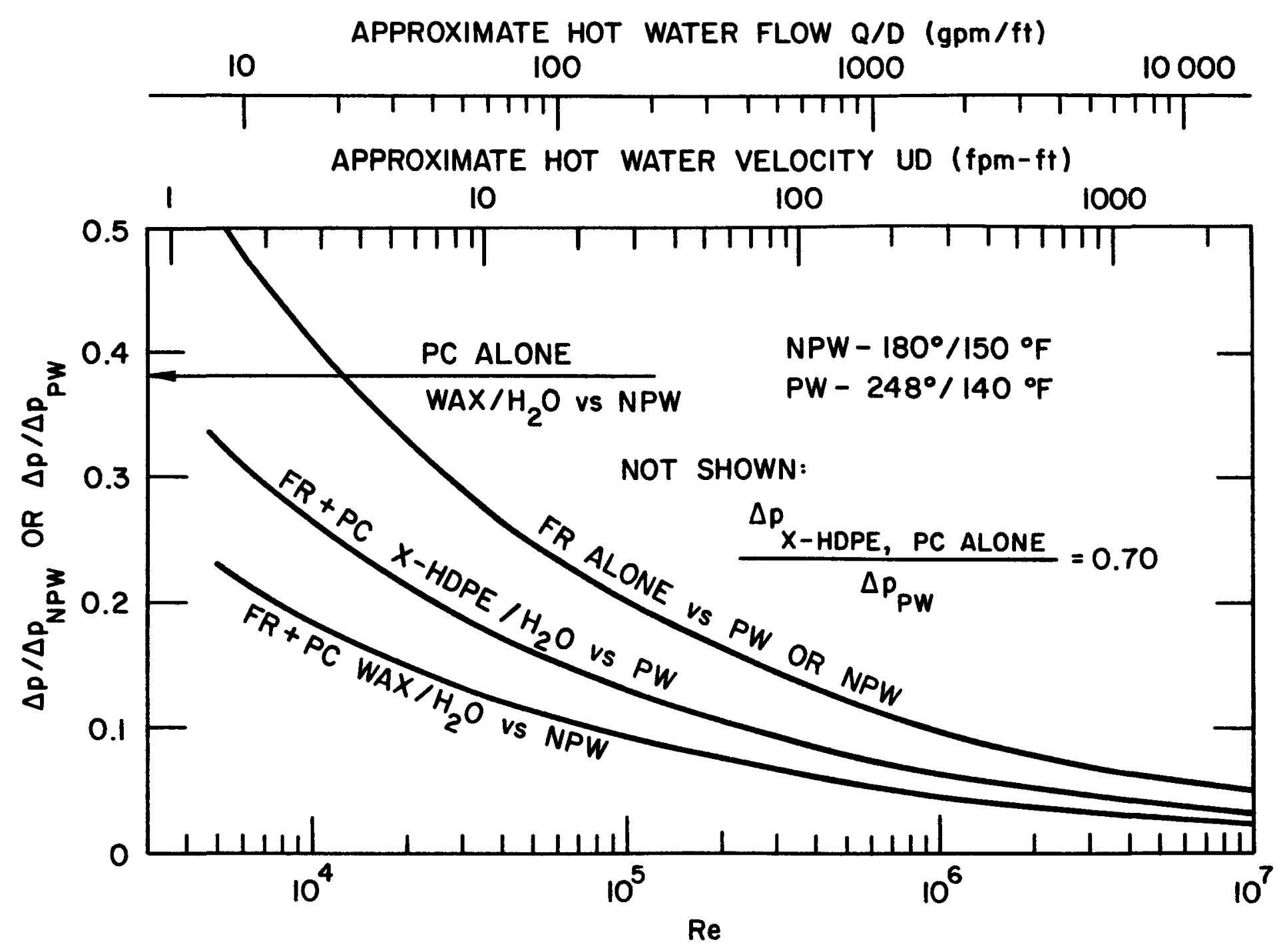

Fig. 20. Pressure Drop Reductions for Constant Pipe Diameter. 


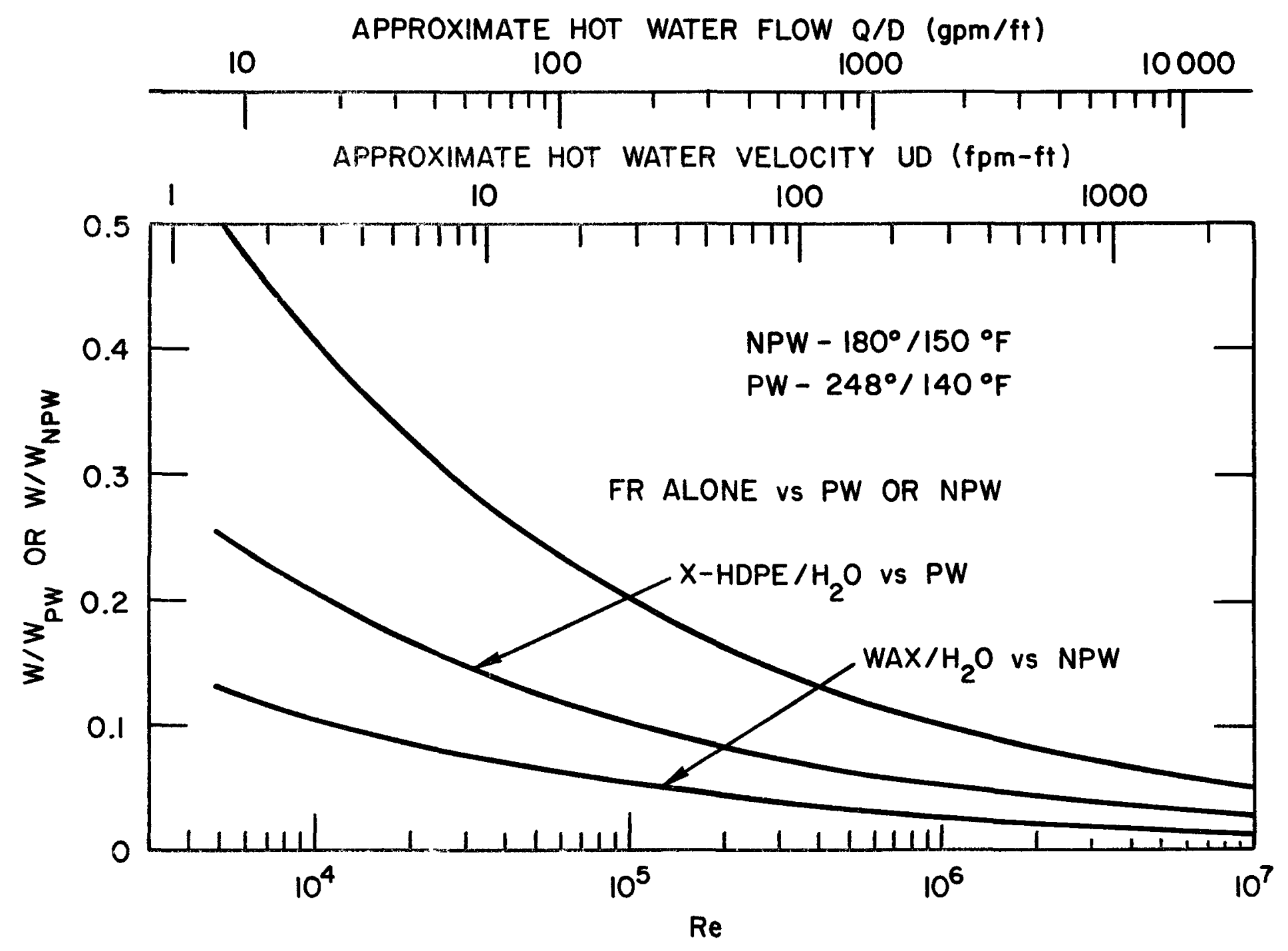

Fig. 21. Pumping Power Reductions for Constant Pipe Diameter. 


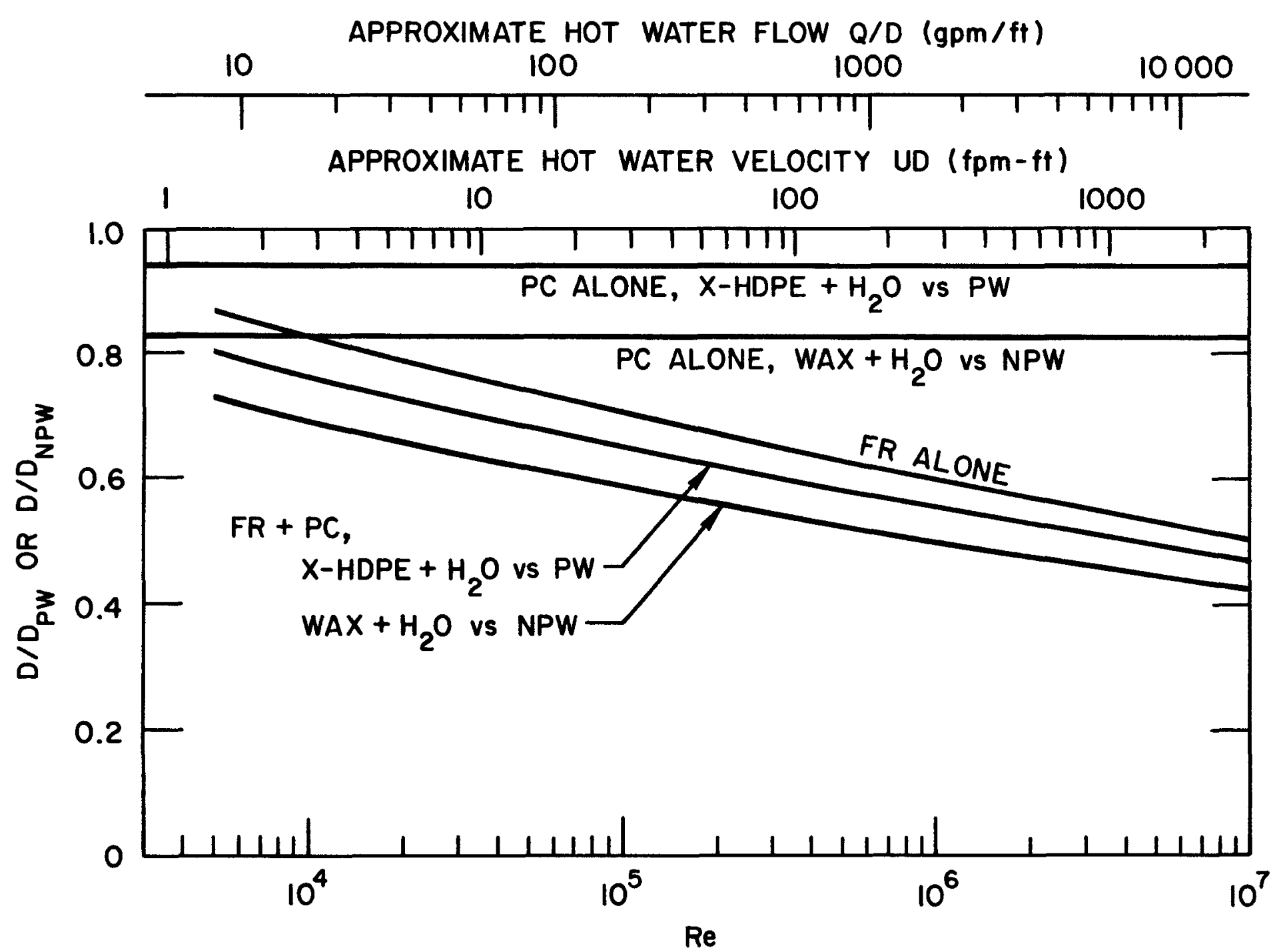

Fig. 22. Pipe Size Reductions at Constant Pressure Drop. 


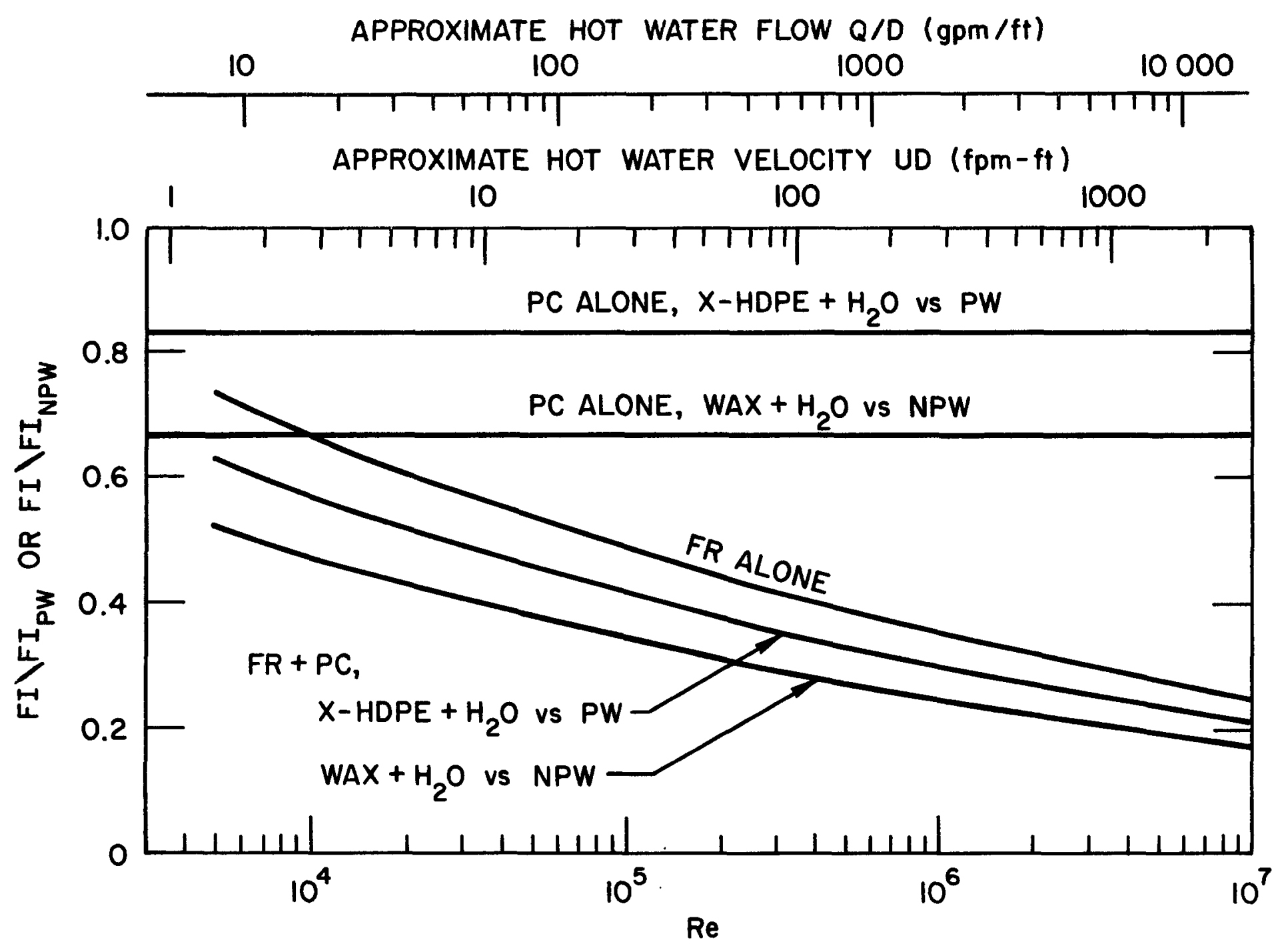

Fig. 23. Fluid Inventory Reductions at Constant Pressure Drop. 


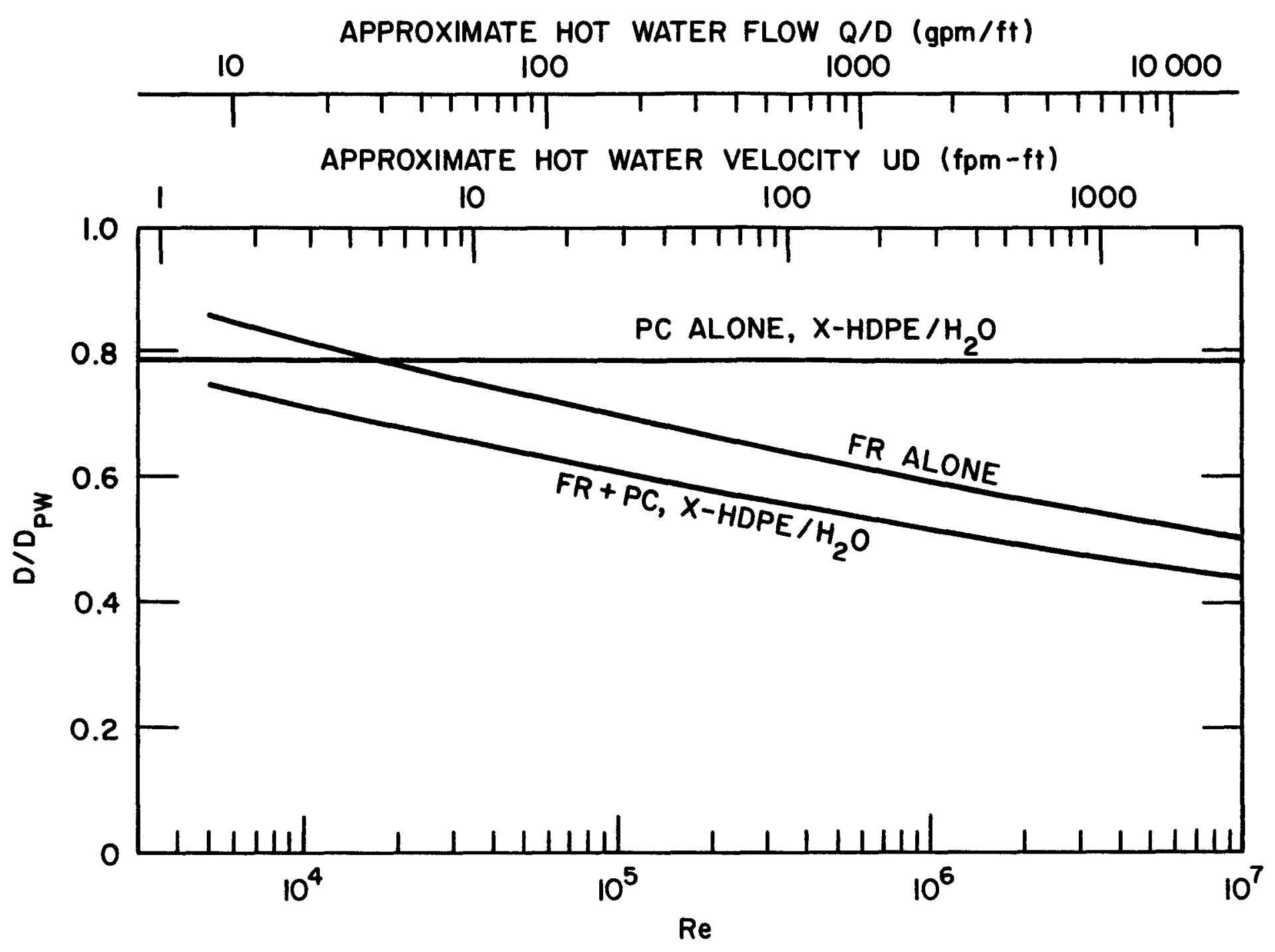

Fig. 24. Pipe Diameter Reductions at Constant Power Compared to Pressurized Water System. 


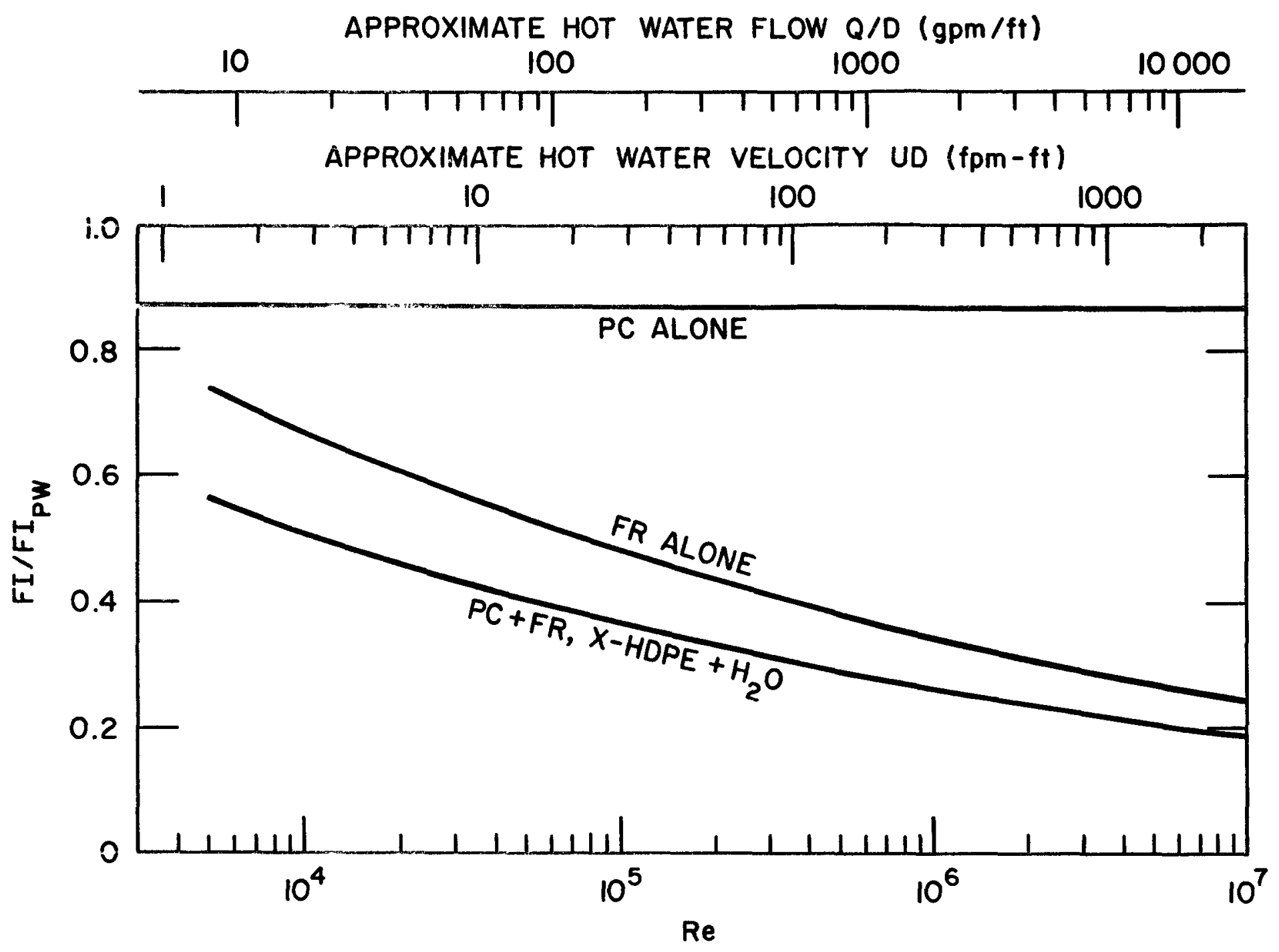

Fig. 25. Fluid Inventory Reductions at Constant Power Compared to Pressurized Water System. 


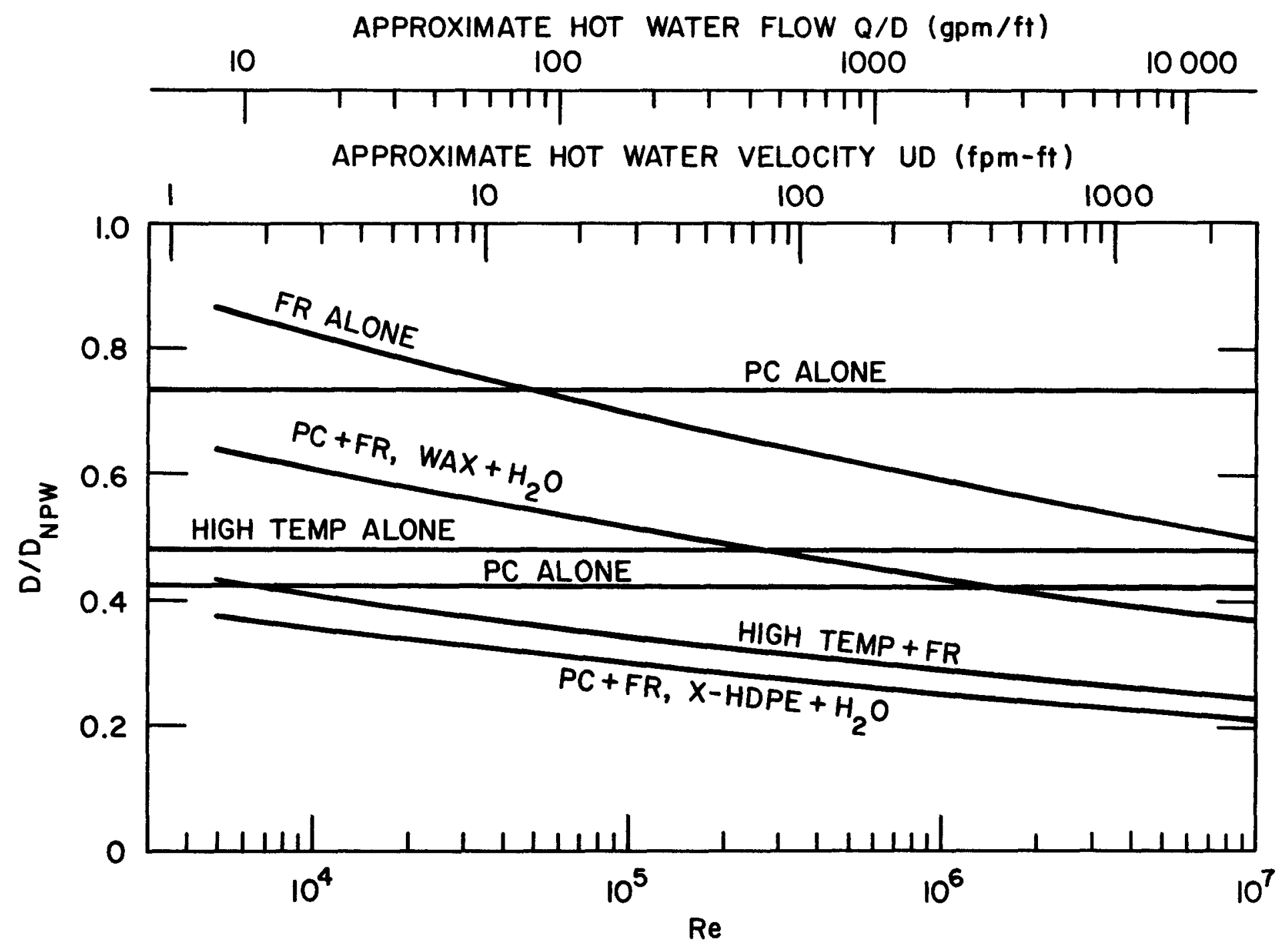

Fig. 26. Pipe Diameter Reductions at Constant Power Compared to Nonpressurized Water System. 


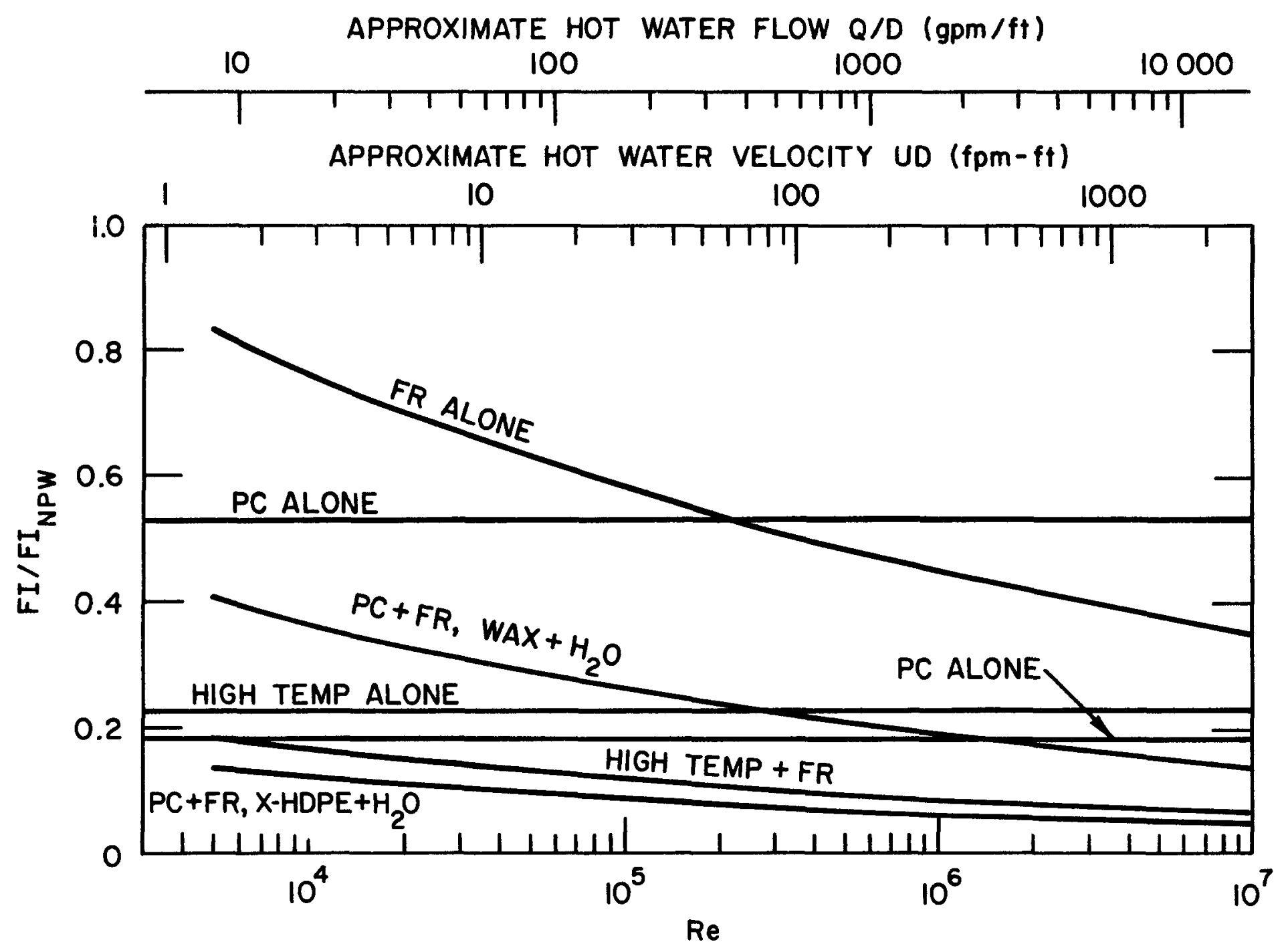

Fig. 27. Fluid Inventory Reductions at Constant Power Compared to Nonpressurized Water System. 


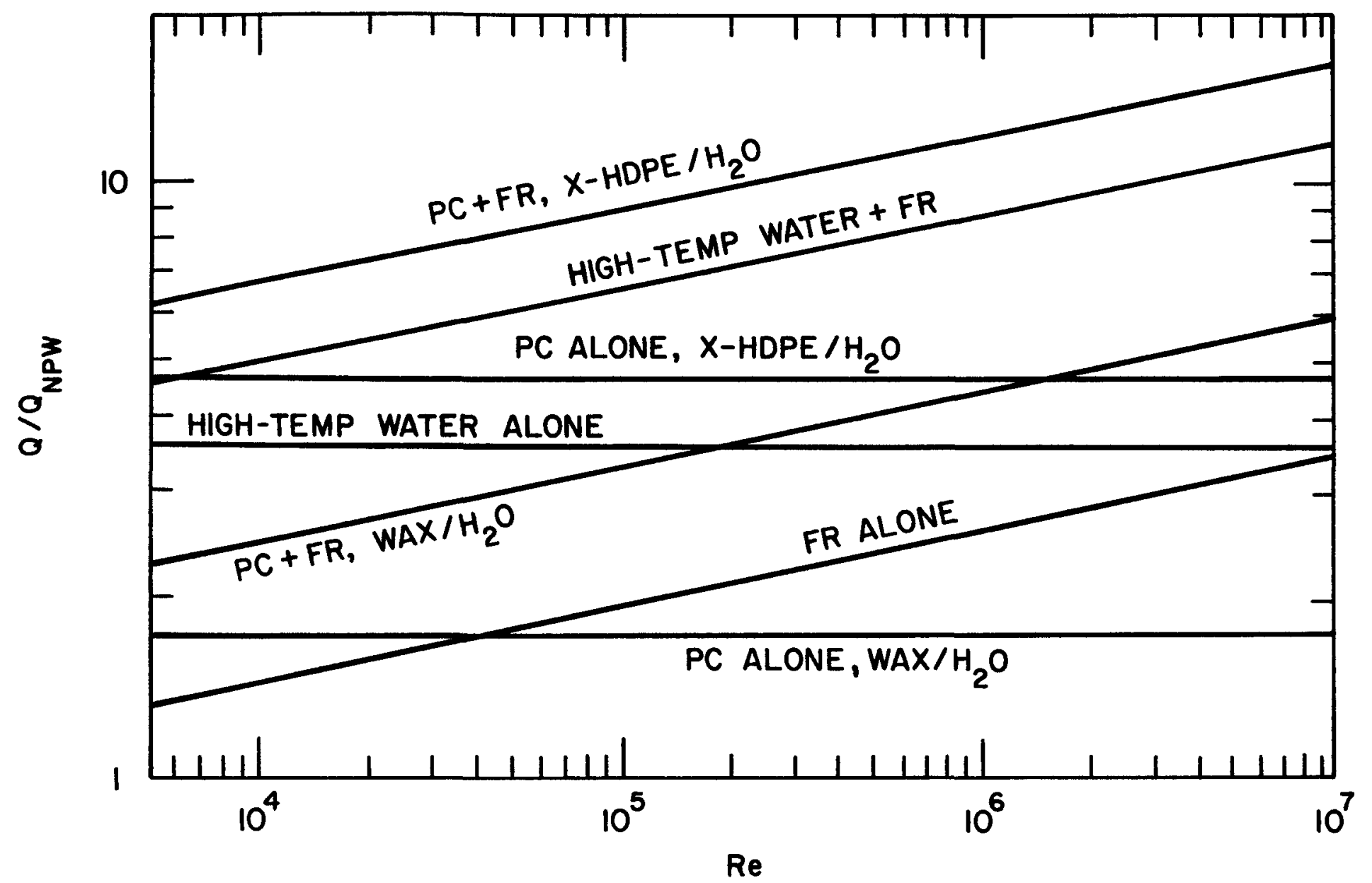

Fig. 28. Increase in Heating Capacity for Advanced Fluids Systems as Compared to Nonpressurized Water in an Existing System. 


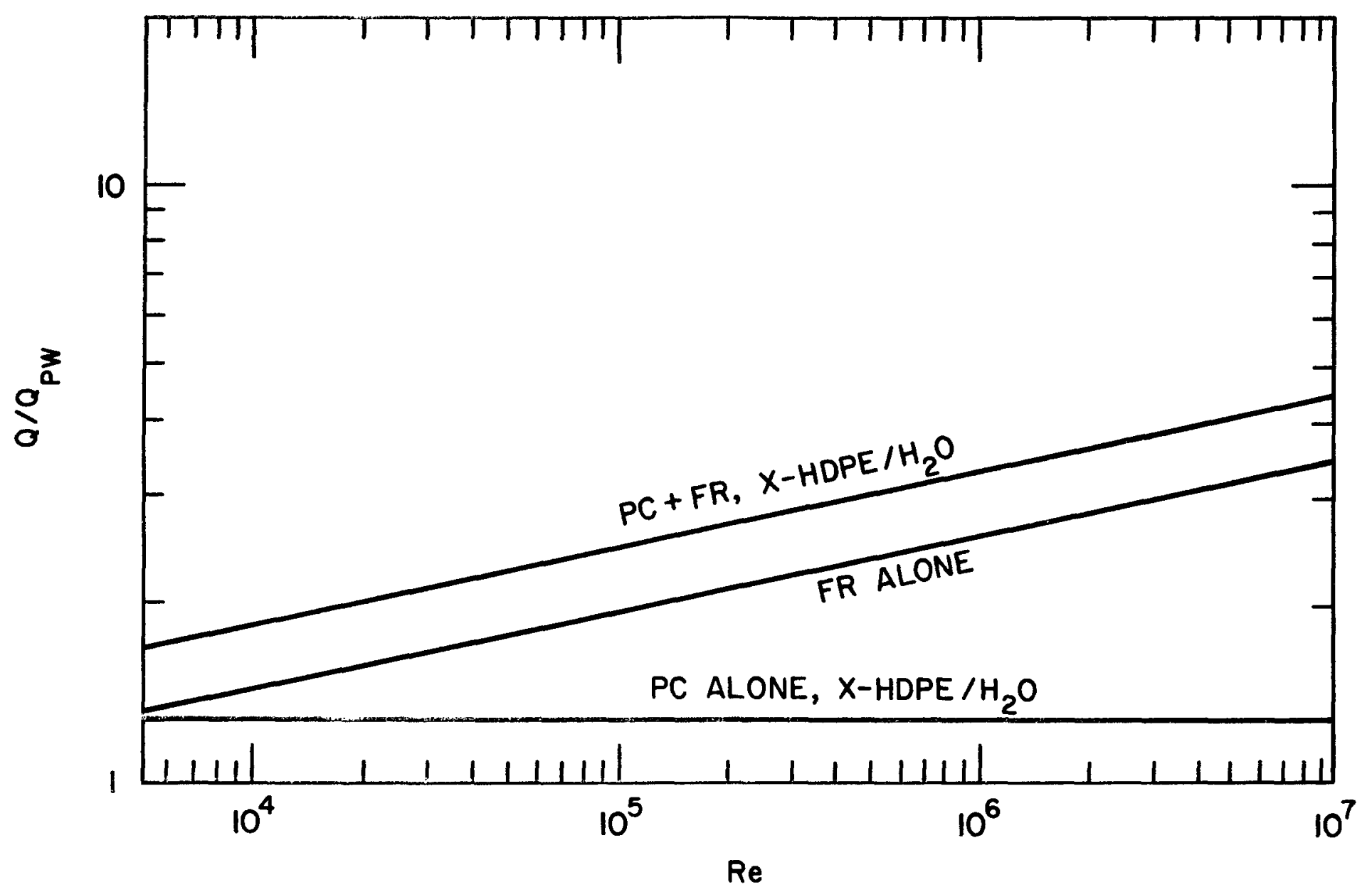

Eig. 29. Increase in Heating Capacity for Advanced Fluids as Compared to Pressurized Water in an Existing System. 


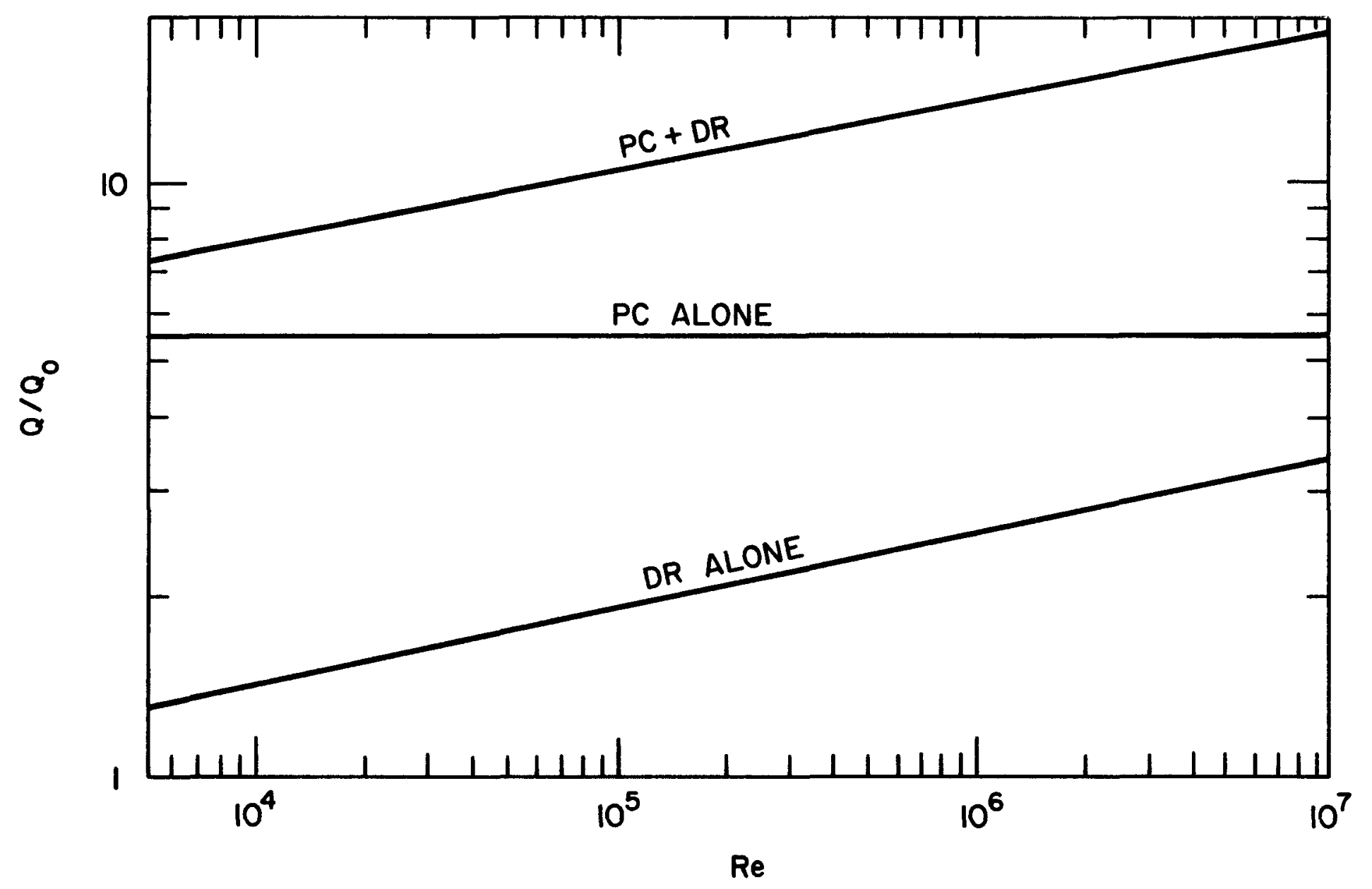

Fig. 30. Increase in Cooling Capacity for Advanced Fluids as Compared to Chilled Water in an Existing Cooling System. 
Distribution for ANL-87-21

Internal:
H. Drucker
W. T. Sha
J. J. Oras
R. W. Weeks
A. Thomas
R. Sehkar
W. W. Schertz
K. E. Kasza (40)
E. M. Stefanski
M. Petrick
M. M. Chen (5)
C. A. Kot
S. U. Choi
ANL Patent Dept.
A. C. Raptis
K. V. Liu
R. E. Holtz
T. M. Kuzay
ANL Contract File
ANL Libraries
TIS Files (5)

External:

DOE-TIC for distribution per UC-95D, UC-59A (356)

Manager, Chicago Operations Office, DOE

Director, Technology Management Division, DOE-CH

D. Chisholm, HTRI

F. Kreith, SERI

P. G. Shewmon, Ohio State University 